\title{
Fecal Carriage of Staphylococcus aureus in the Hospital and Community Setting: A Systematic Review
}

\author{
Shantelle Claassen-Weitz ${ }^{1}$, Adebayo O. Shittu ${ }^{2}$, Michelle R. Ngwarai ${ }^{1}$, Lehana Thabane ${ }^{3}$, \\ Mark P. Nicol ${ }^{1,4,5}$ and Mamadou Kaba ${ }^{1,4 *}$ \\ ${ }^{1}$ Division of Medical Microbiology, Department of Pathology, Faculty of Health Sciences, University of Cape Town, \\ Cape Town, South Africa, ${ }^{2}$ Department of Microbiology, Obafemi Awolowo University, Ile-Ife, Nigeria, ${ }^{3}$ Department of Clinical \\ Epidemiology and Biostatistics, McMaster University, Hamilton, ON, Canada, ${ }^{4}$ Institute of Infectious Disease and Molecular \\ Medicine, Faculty of Health Sciences, University of Cape Town, Cape Town, South Africa, ${ }^{5}$ National Health Laboratory \\ Service of South Africa, Groote Schuur Hospital, Cape Town, South Africa
}

\section{OPEN ACCESS}

Edited by:

Alexandre Gonçalves, Universidade de Trás-os-Montes e Alto Douro, Portugal

Reviewed by:

Dinesh Sriramulu,

Shres Consultancy (Life Sciences), India

Nina Chanishvili, Eliava Institute of Bacteriophages, Microbiology and Virology, Georgia

*Correspondence: Mamadou Kaba mamadou.kaba@hotmail.com; mamadou.kaba@uct.ac.za

Specialty section: This article was submitted to Antimicrobials, Resistance and Chemotherapy, a section of the journal Frontiers in Microbiology

Received: 08 February 2016 Accepted: 18 March 2016

Published: 10 May 2016

Citation:

Claassen-Weitz S, Shittu AO, Ngwarai MR, Thabane L, Nicol MP and Kaba M (2016) Fecal Carriage of Staphylococcus aureus in the Hospital and Community Setting: A Systematic

Review. Front. Microbiol. 7:449. doi: 10.3389/fmicb.2016.00449
Background and rationale: Staphylococcus aureus fecal carriage has been identified as a potential source for nosocomial transmission and a risk factor for disease development. This systematic review determined the overall S. aureus [including methicillin susceptible and resistant $S$. aureus (MSSA and MRSA)] fecal carriage rates within the community and healthcare settings.

Methodology: Peer-reviewed articles indexed in Medline, Scopus, Academic Search Premier, Africa-Wide Information, CINAHL, and Web of Science were identified using applicable and controlled vocabulary through to 11 November 2015. Eligible studies were ascertained by three independent reviewers. Random-effects meta-analyses of proportions were performed to determine S. aureus, MSSA and MRSA fecal carriage rates reported by eligible studies.

Results: Twenty six studies were included in this review. The pooled estimates for S. aureus, MSSA and MRSA fecal carriage were 26\% (95\% confidence interval (Cl): 16.8-36.3\%), 86\% (95\% confidence interval (Cl): 65.9-97.9\%) and 10\% (95\% Cl: $0.7-27.0 \%)$, respectively. Fecal S. aureus carriage rates increased on average from 10 to $65 \%$ during the first 8 weeks of life, followed by an average carriage rate of $64 \%$ at 6 months and $46 \%$ at 1 year of life. Genotyping techniques were employed mainly in studies conducted in developed countries and comprised largely of gel-based techniques. Six studies reported on the role of $S$. aureus fecal strains in diarrhea $(n=2)$ and the risk for acquiring infections ( $n=4)$. Eight of the 26 studies included in this review performed antibiotic susceptibility testing of $S$. aureus fecal isolates.

Conclusion: This study provides evidence that screening for $S$. aureus fecal carriage, at least in populations at high risk, could be an effective measure for the prevention of $S$. aureus transmission and infection in the healthcare and community setting. More well-structured studies need to be conducted and sequence-based genotyping techniques should be employed for the comparison of isolates on a global scale in both developing and developed countries.

Keywords: carriage, community, fecal, Staphylococcus aureus, systematic review 


\section{INTRODUCTION}

Staphylococcus aureus is a commensal Gram-positive bacterium, which under certain circumstances may be responsible for pyogenic or toxigenic infections, such as skin and soft tissue infections, toxic shock syndrome and pneumonia (Tong et al., 2015). Its carriage is considered as an important risk factor for subsequent development of hospital and community-acquired infections (Ellis et al., 2004; Wertheim et al., 2004; Maier et al., 2005; Dukic et al., 2013; Levy et al., 2013). The anterior nares is recognized as the primary site for $S$. aureus colonization (Kluytmans et al., 1997; van Belkum et al., 2009; Sollid et al., 2014). Other anatomical niches for $S$. aureus include the skin (Popov et al., 2014), oropharynx (Mertz et al., 2007; Petersen et al., 2013), intestinal tract (Acton et al., 2009), and the vagina (Bourgeois-Nicolaos et al., 2010).

The importance of fecal carriage of $S$. aureus has been recognized more than five decades ago in a study which demonstrated that rectal $S$. aureus carriage preceded those from the nose and throat in new-borns (Hurst, 1960). Thereafter, several studies have provided evidence on the clinical importance of fecal carriage of $S$. aureus [in particular methicillin-resistant $S$. aureus (MRSA)] in the hospital setting (Acton et al., 2009). For example, it has been shown that hospitalized patients with both $S$. aureus fecal and nasal colonization are significantly more likely to have positive skin cultures compared to patients with nasal carriage only (Bhalla et al., 2007). In addition, $S$. aureus fecal carriage may serve as an important source for environmental contamination, which can potentially facilitate nosocomial transmission within the healthcare setting (Bhalla et al., 2007). Furthermore, antibioticassociated diarrhea attributed to MRSA has also been reported (Lo and Borchardt, 2009; Sizemore et al., 2012; Avery et al., 2015); and patients with MRSA colonized diarrheal stools impact significantly on environmental contamination (Boyce et al., 2007).

Despite the potential role and significance of the sole fecal carriage of S. aureus (Lee et al., 1997; Squier et al., 2002; Bhalla et al., 2007) and the transmission dynamics of $S$. aureus in infection, a limited number of studies have focused on fecal $S$. aureus carriage in the hospital and community setting (Acton et al., 2009). This systematic literature review is therefore aimed to determine the overall rate of $S$. aureus [including methicillin susceptible and resistant S. aureus (MSSA and MRSA)] fecal carriage amongst individuals in the community and healthcare settings.

\section{METHODOLOGY}

This review followed the preferred reporting items for systematic reviews and meta-analyses (PRISMA) guidelines (Moher et al., 2009). The PRISMA check-list for this review is provided in a Supplementary Table (Table S1).

\section{Literature Search Strategy}

Peer-reviewed articles (written in English and French) published through to 11 November 2015 on S. aureus fecal carriage within the community and healthcare settings were evaluated using four electronic databases and a combination of keywords (Table 1). We also explored for additional articles by checking the references cited in the primary eligible studies included in this systematic review.

\section{Study Selection and Data Extraction}

Potentially relevant articles (selected based on their titles and abstracts) were assessed for eligibility (Table 2) by three independent authors. All potentially eligible articles were screened for "predatory journals" using "Beall's list" (Beall, 2015; Shen and Björk, 2015; Siebert et al., 2015). The corresponding authors of potentially relevant articles were contacted to determine the healthcare exposure status of participants so as to assess their eligibility for inclusion in this systematic review (Table 2). Data extraction was performed independently by two authors using a standardized data extraction form. Disagreements and inconsistencies were resolved by consensus. The following information was extracted from each eligible study: study population, number of participants screened for fecal carriage, participant characteristics (age, health status, exposure to health care settings), sample collection details (sample type, age at which samples were collected, collection site), laboratory techniques (S. aureus and MRSA screening methods, genotyping techniques, virulence profile assessment), as well as S. aureus and MRSA detection rates.

\section{Operational Definitions of Terms Used in this Systematic Review \\ Community Setting \\ Healthy participants}

- Participants reported to be healthy at the time of screening for S. aureus or MRSA fecal carriage without any exposure to healthcare settings during the year preceding screening (McKinnell et al., 2013);

TABLE 1 | Search strategy performed in four databases.

\begin{tabular}{|c|c|c|}
\hline Database & Search mode & Keywords \\
\hline Medline via Pubmed & All fields & \multirow{3}{*}{$\begin{array}{l}\text { ("staphylococcus aureus") AND ("gut" OR "gastrointestinal" OR "anal" OR "anus" OR } \\
\text { "intestinal" OR "rectum" OR "rectal" OR "stool" OR "feces" OR "faeces" OR "fecal" } \\
\text { OR "faecal") AND ("epidemiology" OR "incidence" OR "prevalence" OR "carriage" OR } \\
\text { "carriage rate" OR carrier*) AND ("humans" OR "human") }\end{array}$} \\
\hline Scopus via SciVerse & Article title, abstract, keywords & \\
\hline $\begin{array}{l}\text { Academic Search Premier, Africa-Wide } \\
\text { Information and CINAHL via EBSCOHost }\end{array}$ & Boolean/Phrase & \\
\hline Web of Science via Web of Knowledge & Topic & \\
\hline
\end{tabular}


TABLE 2 | Eligibility criteria.

Inclusion criteria for systematic review

- Studies published from 1920 to 11 November 2015 were included in the search.

- Studies reporting on S. aureus or MRSA carriage from fecal/rectal/anal specimens from humans.

- Studies providing information on the prevalence of S. aureus or MRSA fecal carriage.

- Healthcare exposure data should include information on whether or not participants were:

1. Hospitalized in the 12 months prior to screening nursing home residents, health care workers, or patients transferred from other hospitals or wards (McKinnell et al., 2013).

2. Screened for $S$. aureus or MRSA fecal carriage within $>$ or $\leq 48$ hours of healthcare contact (Folden et al., 2005; Millar et al., 2007; Otter and French, 2011).

- Studies published in either English or French.
Exclusion criteria for systematic review

- Studies screening for S. aureus or MRSA from samples other than feces/recta swabs/anal swabs.

- Fecal samples studied for parasites or bacteria other than S. aureus.

- Articles reporting on the number of $S$. aureus or MRSA isolates detected from fecal specimens or on the number of fecal specimens positive for $S$. aureus or MRSA, but not providing information on the number of participants testing positive for $S$. aureus or MRSA fecal carriage.

- Studies not providing the necessary healthcare exposure data for participants (via the published article or via correspondence with the authors), in order to categorize participants into Healthy participants, Out-patients, In-patients and Healthcare personnel.

- Articles published in predatory journals (Beall, 2015).

- Articles not obtainable from the electronic databases, the University of Cape Town (UCT) library or the UCT inter-library loans.
Inclusion criteria for meta-analysis of proportions

- Overall fecal carriage prevalence for S. aureus and/or MRSA must be available.
Exclusion criteria for meta-analysis of proportions

- Studies providing fecal carriage rates for participants for which fecal carriage rates have previously been reported.

- Studies not providing information on the age at which participants were screened.

- Studies screening a pre-selected group of participants based on microbiological assessments.

- Studies for which MRSA was not confirmed using molecular methods.
- Pregnant women visiting obstetric clinics;

- New-borns and mothers at maternity wards during the time of delivery;

- Mothers and infants reported as healthy at the time of screening for S. aureus or MRSA fecal carriage, but exposed to the delivery unit or maternity ward during the year preceding screening.

\section{Out-patients}

Patients screened for $S$. aureus or MRSA fecal carriage with $\leq 48$ h of healthcare contact (Folden et al., 2005; Millar et al., 2007; Otter and French, 2011). Patients should not have had contact with healthcare settings in the year preceding the study.

\section{Healthcare Setting In-patients}

Patients screened for $S$. aureus or MRSA fecal carriage with $>48 \mathrm{~h}$ of healthcare contact. Patients screened within $\leq 48$ $\mathrm{h}$ after admission should be those transferred from another hospital/ward which will allow for $>48 \mathrm{~h}$ of hospital contact.

\section{Healthcare personnel}

Participants screened for $S$. aureus or MRSA fecal carriage working at a healthcare setting with or without any illness.

\section{Developed and Developing Countries}

Countries were categorized as developed or developing countries based on data from the International Monetary Fund (http:// www.imf.org/external/pubs/ft/weo/2015/01/weodata/groups. htm).

\section{Antibiotic Susceptibility Results}

The percentage of isolates (obtained from participants with $S$. aureus or MRSA fecal carriage) resistant to each of the antibiotics assayed was calculated from studies that provided adequate data on antibiotic susceptibility test results. Our review noted susceptibility tests results whether or not the respective studies incorporated published guidelines [such as Clinical Laboratory Standards Institute (CLSI), National Committee on Clinical Laboratory Standards (NCCLS), European Committee on Antimicrobial Susceptibility Testing (EUCAST), Antibiogram Committee of the French Society of Microbiology (CA-SFM), or the Swedish Reference Group for Antibiotics (SRGA) guidelines] in assessing the antibiotic resistance profiles.

\section{Statistical Analysis and Data Visualization}

The S. aureus, MRSA and MSSA fecal carriage rates for studies included in this systematic review were calculated as follows:

S. aureus fecal carriage rate $(\%)=$ Participants positive for $S$. aureus fecal carriage Participants screened for $S$. aureus fecal carriage

MRSA fecal carriage rate $(\%)=$

Participants positive for MRSA fecal carriage

Participants screened for S. aureus or MRSA fecal carriage MSSA fecal carriage rate $(\%)=$

(Participants positive for $S$. aureus fecal carriage - Participants positive for MRSA fecal carriage)

Participants screened for $S$. aureus fecal carriage 
Individual reports assessing the same participants for $S$. aureus, MSSA or MRSA fecal carriage were considered as a single report. Calculated fecal $S$. aureus carriage rates were used to derive longitudinal data of individual studies, as well as the average carriage rate amongst these studies, at each time-point. Meta-analyses of proportions were performed to determine the overall S. aureus, MSSA and MRSA fecal carriage rates (pooled estimates) among individuals in the community and healthcare settings. Meta-analyses of proportions for MRSA and MSSA did not include studies for which MRSA was not confirmed using molecular methods. For all meta-analyses of proportions, studies screening for MRSA amongst pre-selected vancomycin resistant enterococci (VRE) fecal carriers were excluded. Similarly, meta-analyses of proportions did not include studies that screened for MRSA fecal carriage solely from preselected MRSA carriers (MRSA identified from other body sites). Meta-analyses were performed using StatsDirect statistical software version 3.0.165 [England: StatsDirect Ltd. 2016] for studies adhering to the inclusion criteria summarized in Table 2. The StatsDirect statistical software version 3.0.165 [England: StatsDirect Ltd. 2016] was also applied to assess the heterogeneity between the studies included in the meta-analyses (Cochran Qtest) (Cochran, 1954) and to determine the inconsistency across the studies included ( $I^{2}$ statistic) (Higgins et al., 2003). The criterion for statistical significance for the test for heterogeneity was set at alpha $=0.05$. The risk of publication bias was assessed and visualized by a Funnel plot (Egger et al., 1997; Sterne et al., 2011).

\section{RESULTS}

\section{Study Selection and Characteristics \\ S. aureus Study Selection}

Figure 1 outlines the study selection process and the broad reasons for exclusion. The search strategy identified 2522 records. An additional record was identified from the reference list of one of the eligible articles included in the review. A total of 124 potentially eligible reports were identified, of which 69 fulfilled the primary inclusion criteria (Figure 1). The vast majority $(80 \%$; $55 / 69)$ of these potentially eligible articles did not provide information on healthcare exposure during the year preceding screening and/or did not indicate the duration for which patients were admitted prior to the time of screening. Following correspondence with authors, seven articles were excluded as these reports did not fulfill our inclusion criteria. Moreover, 36 articles were excluded due to lack of required information from corresponding authors or as a result of unavailable author contact information. Consequently, only 26 (11 and 15 reports based on their full texts and information obtained from the authors, respectively) of the 69 studies could be included in our systematic review. The main findings reported by each of the 26 eligible studies are summarized in detail in Tables 3, 4. Select studies that screened for $S$. aureus fecal carriage from both community and healthcare settings are also reported accordingly in Tables 3, 4.

\section{Characteristics of Reports from Community and Healthcare Settings}

\section{Reports on $S$. aureus fecal carriage}

A total of 19 reports investigated fecal $S$. aureus carriage within the community setting, of which five and 14 studies reported on fecal carriage rates from outpatients and healthy participants, respectively (Table 3). Moreover, the majority $(64 \%$; $9 / 14)$ of reports on fecal $S$. aureus carriage rates from healthy participants were of longitudinal design and investigated infants up until one year of age (Table 3 ). Of the five reports on fecal carriage rates from outpatients, a single study performed a longitudinal analysis of $S$. aureus fecal carriage (Efuntoye and Adetosoye, 2003) and another investigated infants during the first year of life (Shehabi et al., 2013). Study sizes for the community setting ranged between 21 and 1761 participants (Table 3 ).

Fecal S. aureus carriage within the healthcare setting was noted in 12 reports (Table 4). Of these, 10 were from inpatients and two from healthcare personnel. All reports on inpatients were of cross-sectional design and the majority $(60 \% ; 6 / 10)$ did not provide information on the age of the participants. In addition, the two studies on healthcare personnel were crosssectional in design and carried out in the United States of America (USA) (Carmeli et al., 1998; Andrews et al., 2009). Study sizes for healthcare-based reports ranged between 37 and 2727 participants (Table 4).

\section{Reports on methicillin susceptible and resistant S. aureus fecal carriage}

Six of the 19 reports on S. aureus fecal carriage from the community setting provided MRSA fecal carriage rates confirmed by molecular methods (Table 3). Five of these studies (conducted in developed countries) reported both $S$. aureus and MRSA fecal carriage rates which allowed for the calculation of MSSA fecal carriage rates. Only one study within the healthcare setting (conducted in the USA) confirmed fecal MRSA carriage by screening specimens using a molecular approach (Andrews et al., 2009).

\section{Pooled Estimates of S. aureus Fecal Carriage Rates Assessed by Meta-Analyses}

Studies included in all of the proportional meta-analyses were heterogeneous, as determined by the Cochrane Q test and $I^{2}$ statistic (Figures 2-4). We could not determine pooled MSSA or MRSA fecal carriage rates within the healthcare setting as only a single study was considered eligible for this analysis.

The pooled random-effects estimate for $S$. aureus fecal carriage within the community and healthcare settings was $26 \%$ (95\% CI $=16.8-36.3$; Figure 5). Sub-analyses of S. aureus fecal carriage within the community and healthcare settings resulted in pooled random-effects estimates of $31 \%(95 \% C I=17.8-46.3)$ and 5\% (95\% CI $=1.7-8.9)$, respectively.

MSSA fecal carriage was estimated at $86 \%$ (95\% CI $=65.9-$ 97.9) using the random-effects model (Figure 6). Within the community setting, the random effects estimate for MSSA fecal 


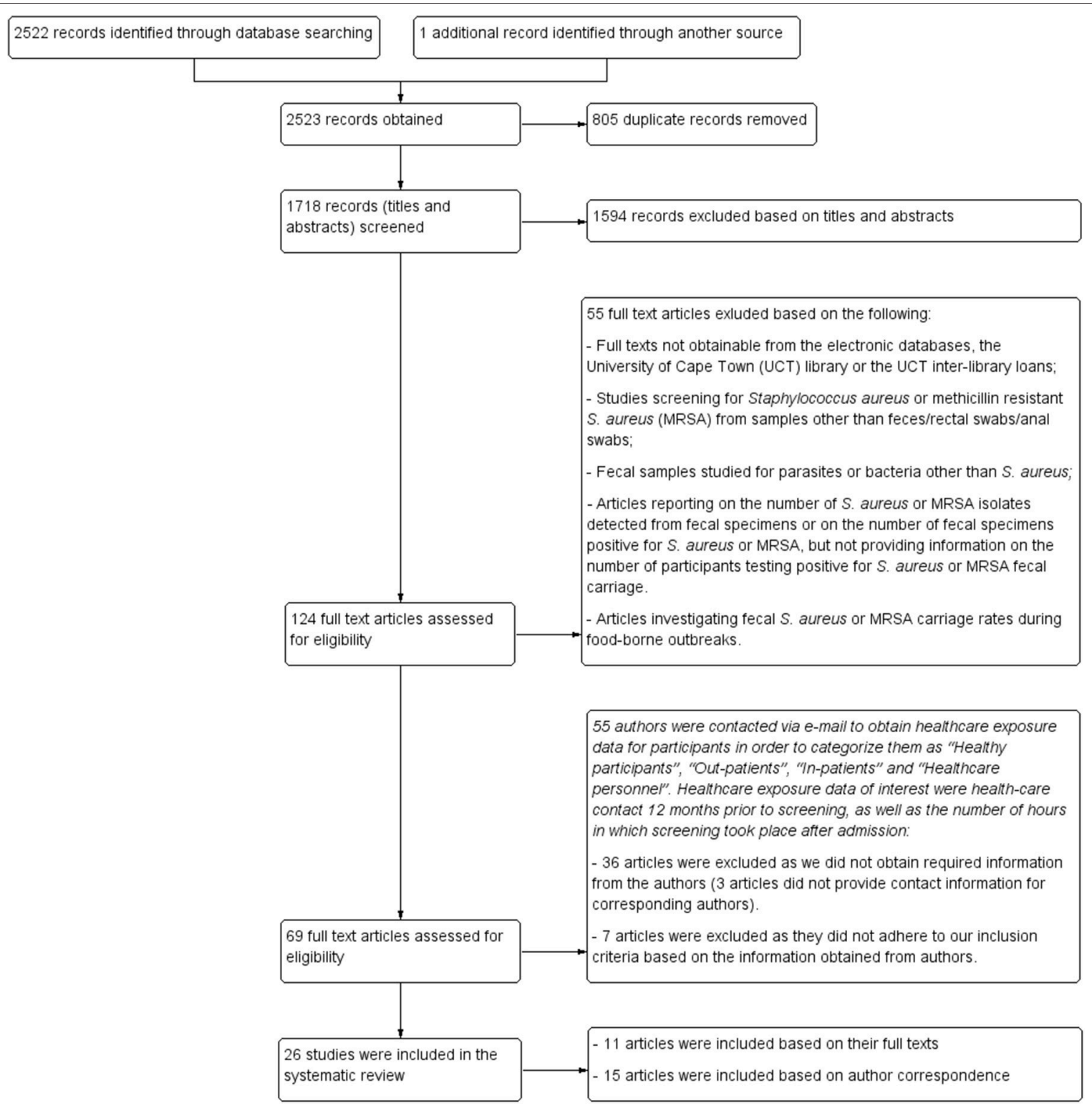

FIGURE 1 | Study selection. Flow diagram of identification and selection process for studies included in the systematic review.

carriage was $86 \%$ (95\% CI $=62.3-98.5)$. The pooled randomeffects estimates for MRSA fecal carriage were $10 \%$ (95\% CI = $0.7-27.0$; Figure 7); and $10 \%(95 \% C I=0.4-28.9)$ within the community setting.

\section{S. aureus Fecal Carriage Rates According to the Age of Participants}

The report on this section is not based on meta-analysis. S. aureus fecal carriage rates within the community setting were higher during the first year of life (Figure 8). On average, reports from longitudinal studies revealed an increase in $S$. aureus fecal carriage rates from approximately $10-65 \%$ during the first 8 weeks of life (Figure 8). At 6 months of age, the average fecal carriage rate was $64 \%$, thereafter it decreased to approximately $46 \%$ at 1 year of life. A longitudinal investigation of fecal MRSA carriage rates from healthy participants from the USA showed an increase in fecal MRSA carriage from 0 to $9 \%$ during the first 2 weeks of life (Gries et al., 2009). The highest MRSA fecal carriage rate $(23 \%)$ reported was from Spanish infants screened at $\leq 1$ year of life (Benito et al., 2015).

\section{Assessment of Antibiotic Susceptibility of Fecal S. aureus Isolates}

Eight of the 26 eligible studies (31\%) included in this review assayed for antibiotic susceptibility of fecal S. aureus or MRSA isolates (Table 5). Overall, S. aureus or MRSA isolates were 


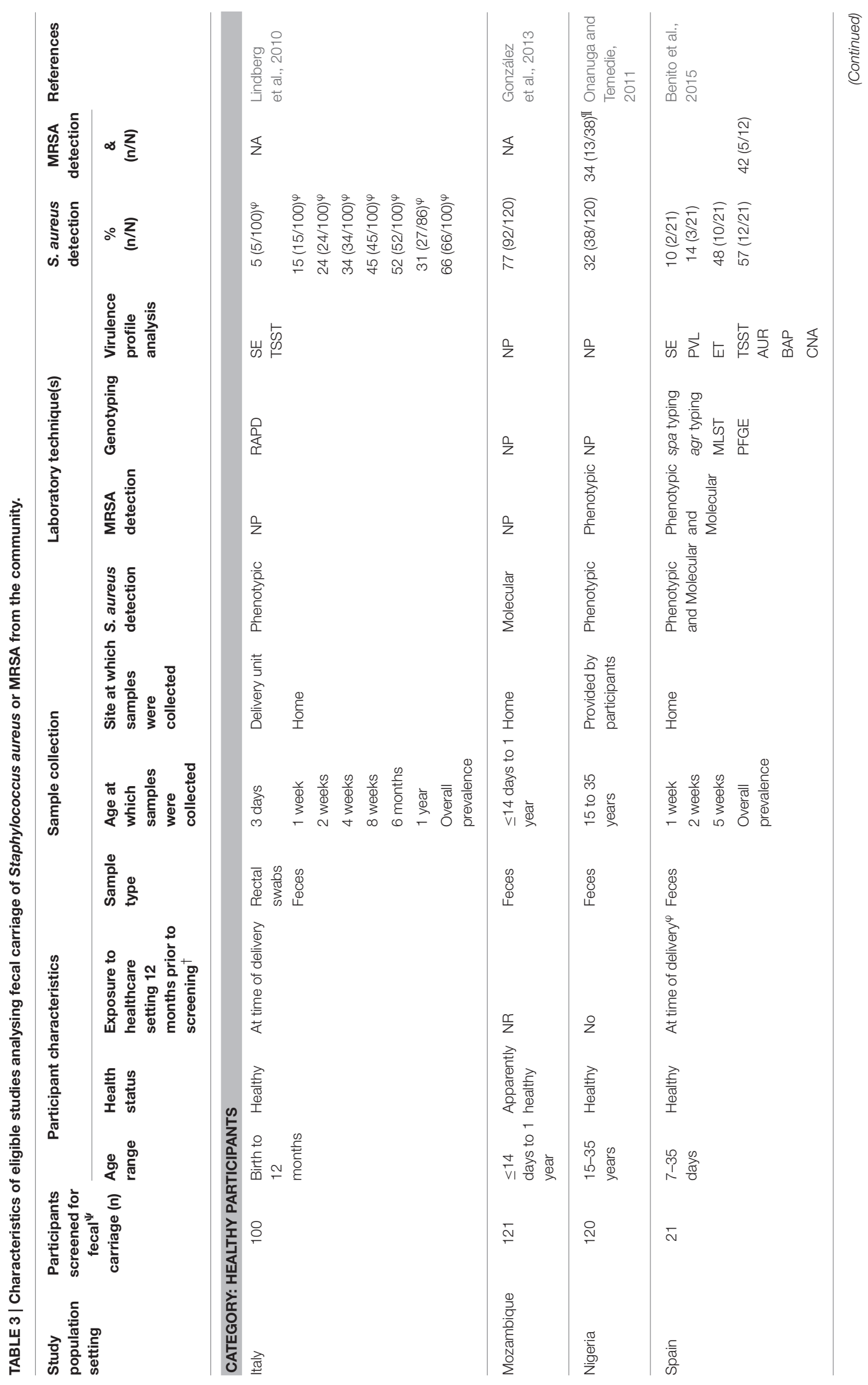




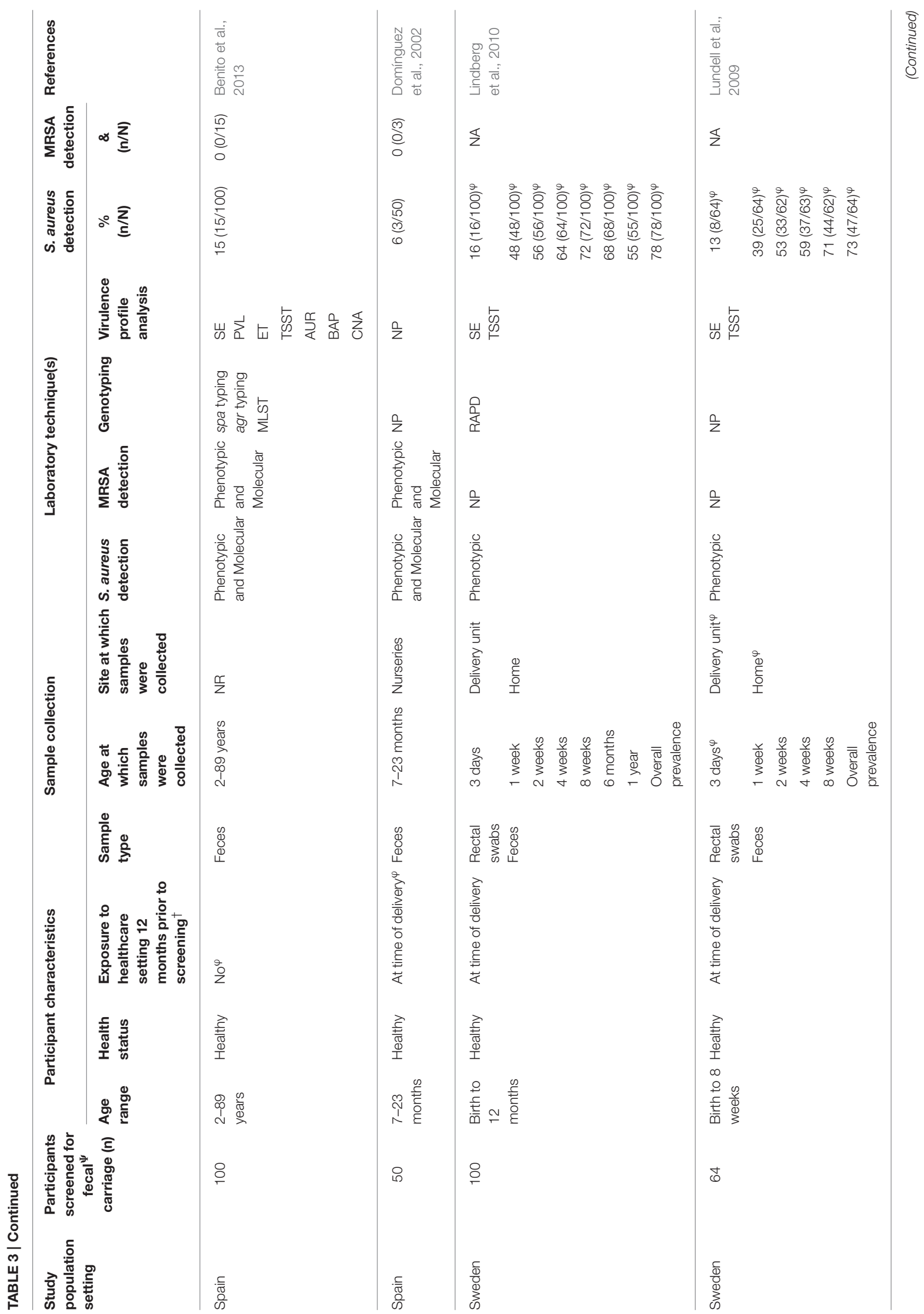




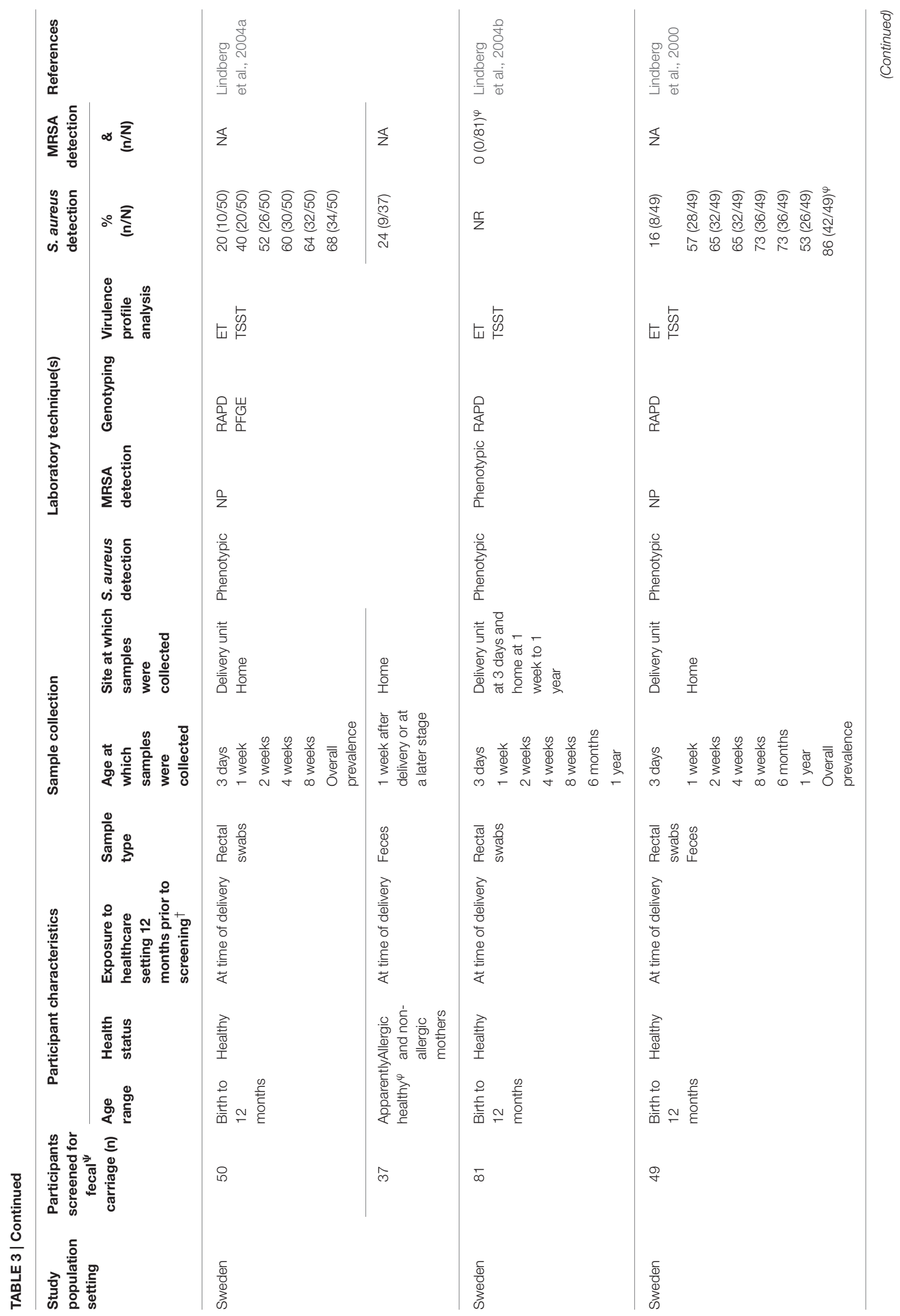




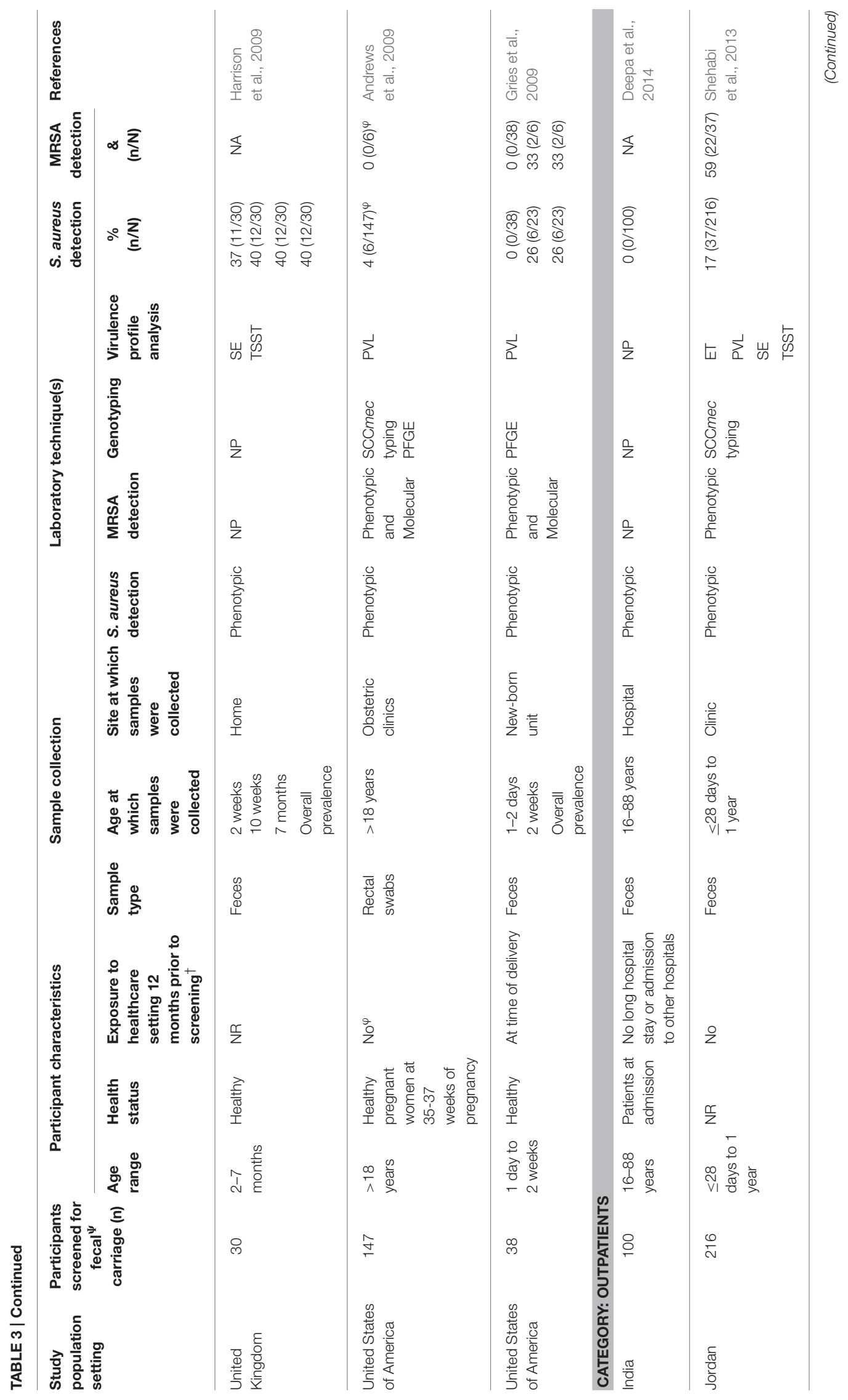




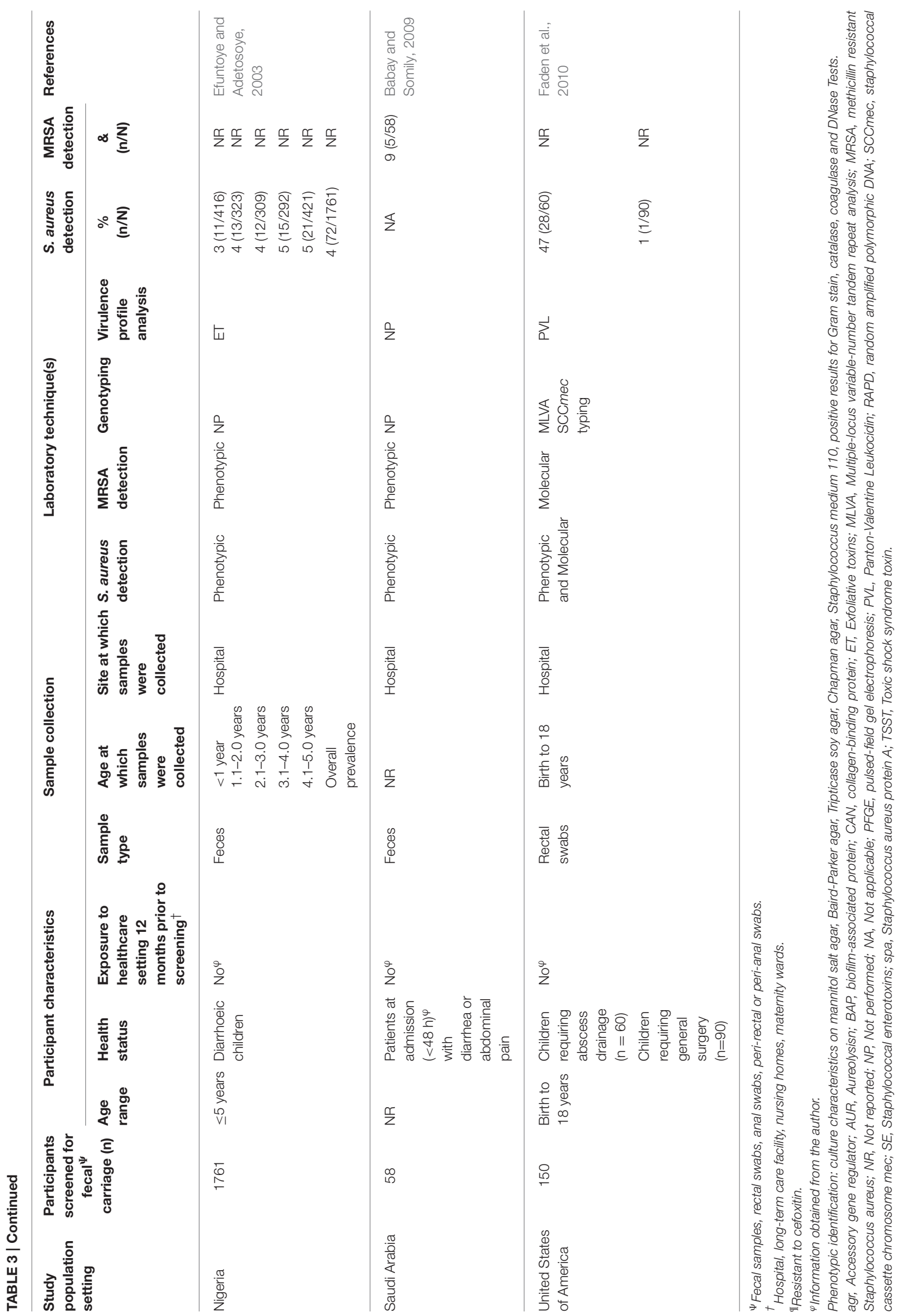




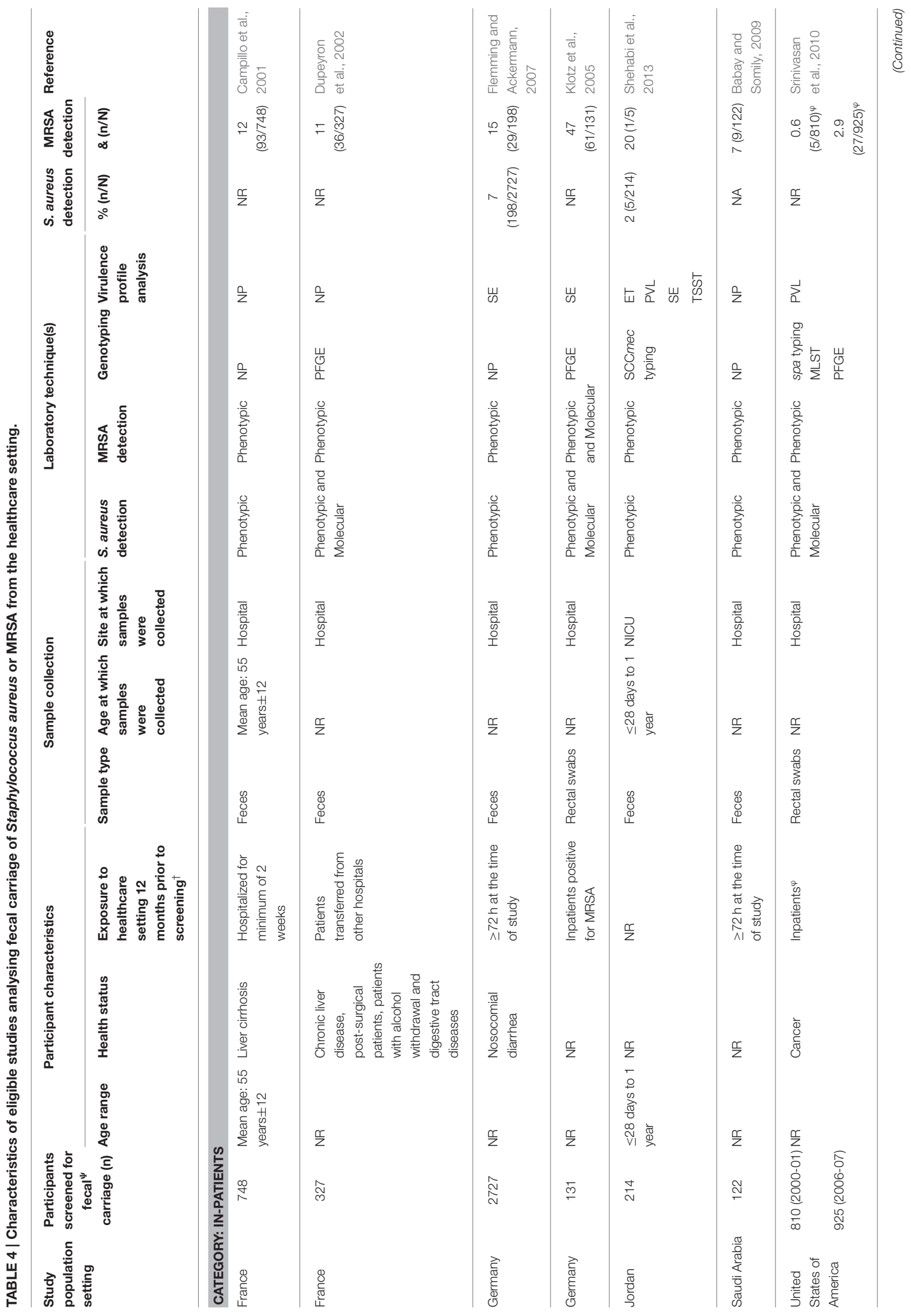




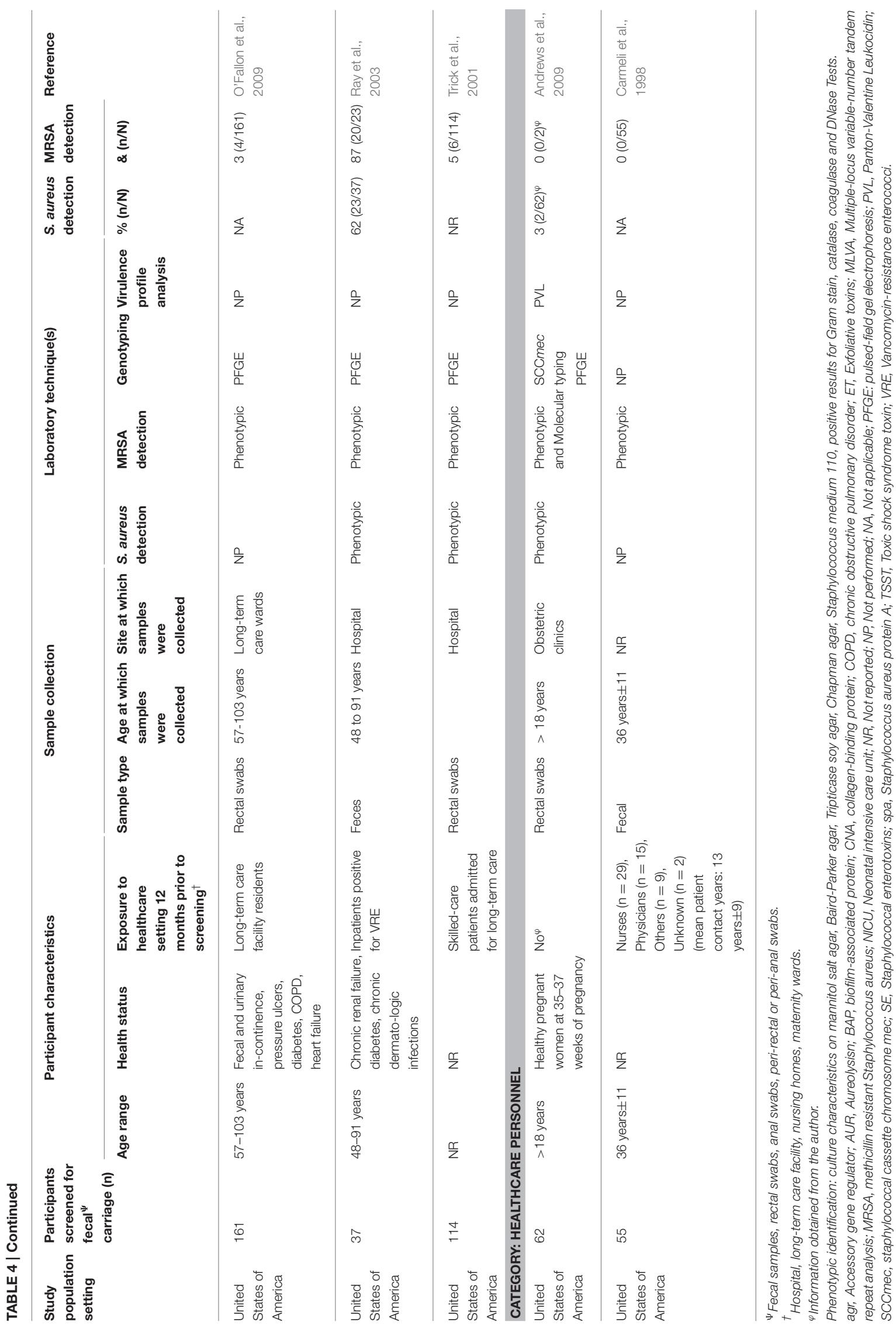




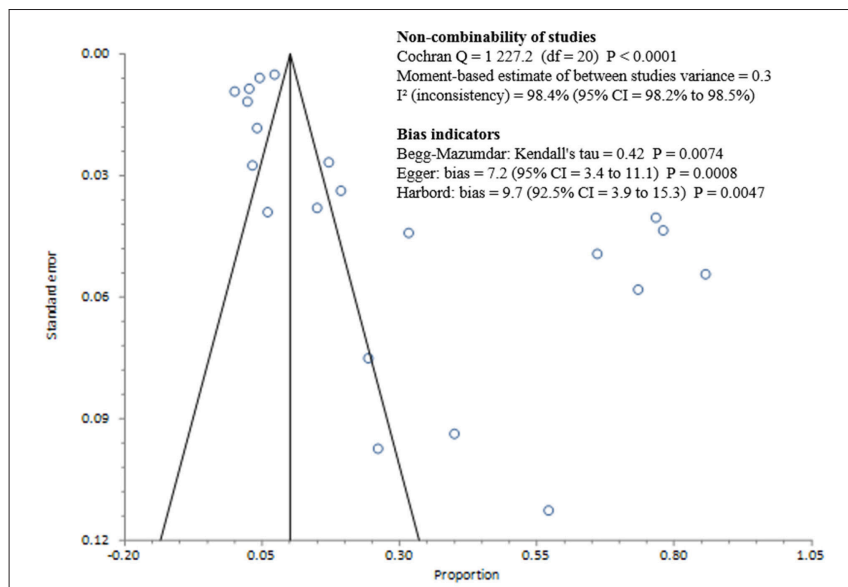

FIGURE 2 | Bias assessment (Funnel) plot for studies assessing Staphylococcus aureus fecal carriage rates.

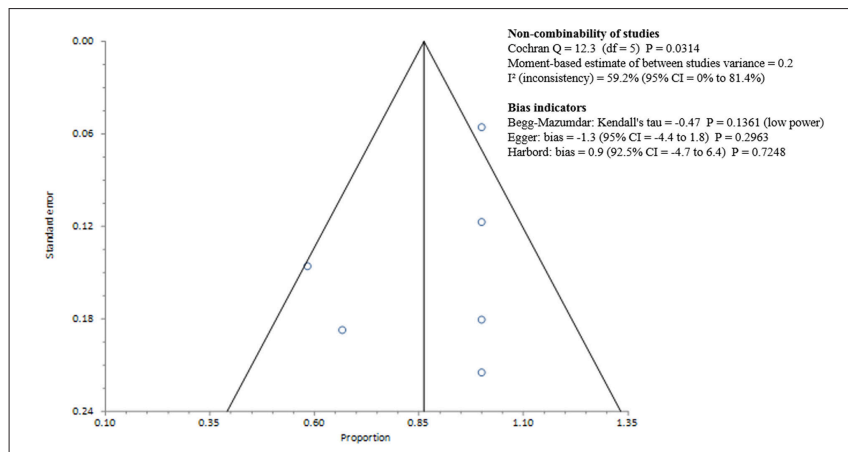

FIGURE 3 | Bias assessment (Funnel) plot for studies assessing Methicillin susceptible Staphylococcus aureus fecal carriage rates.

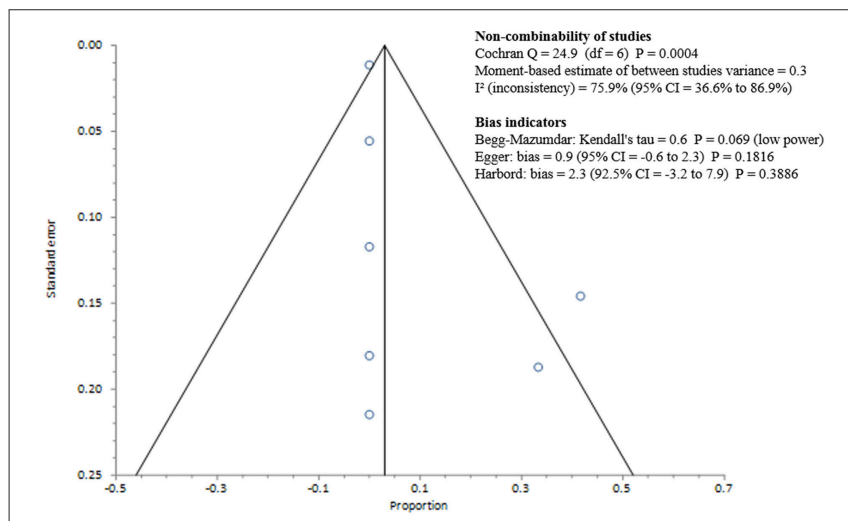

FIGURE 4 | Bias assessment (Funnel) plot for studies assessing Methicillin resistant Staphylococcus aureus fecal carriage rates.

screened with 32 different antibiotics across the respective studies using disk diffusion, agar dilution, or the Vitek Legacy System. The use of published guidelines for susceptibility testing were reported by six of the eight studies (Table 5). Susceptibility testing to erythromycin was performed most frequently $(88 \%$;
7/8), followed by chloramphenicol, clindamycin, ciprofloxacin, gentamicin, penicillin and vancomycin (75\%; 6/8) (Table 5). Vancomycin intermediate or resistant S. aureus (VISA/VRSA) were not identified in five of the six studies that screened for vancomycin resistance (Table 5). Only the study by Onanuga and Temedie (2011) reported fecal VRSA carriage of $37 \%$ (14/38).

\section{Genotyping of S. aureus Isolated from Fecal Specimens}

Techniques used to genotype $S$. aureus isolated from fecal specimens included multiple-locus variable-number tandem repeat analysis (MLVA), pulsed-field gel electrophoresis (PFGE), random amplified polymorphic DNA (RAPD) analysis, staphylococcal cassette chromosome mec (SCCmec), accessory gene regulator (agr) and Staphylococcus aureus protein A (spa) typing (Tables 3,4$)$. Genotyping was performed in slightly more reports from the healthcare setting $(67 \% ; 8 / 12)$ compared to the community $(58 \% ; 11 / 19)$. Gel-based methods (PFGE, RAPD and MLVA) were employed in 58\% (7/12) and $42 \%(8 / 19)$ of studies in the healthcare and community settings, respectively. In addition, similar rates (26\% vs. $25 \%$ ) in the use of sequence-based methods (spa typing, SCCmec typing and MLST) for genotyping of $S$. aureus strains were reported from community and healthcare settings. Only a single study conducted in a developing country (Jordan) performed genotyping of the S. aureus strains (Shehabi et al., 2013).

\section{Assessment of the Detection of S. aureus Virulence Genes}

Virulence genes screened included the aureolysin enzyme, biofilm-associated protein, collagen-binding protein, exfoliative toxins (ETs), staphylococcal enterotoxins (SEs), toxic shock syndrome toxin (TSST), and Panton-Valentine leukocidin (PVL) (Tables 3, 4). More community-based investigations screened for $S$. aureus virulence genes compared to reports from the healthcare setting. Thus, 53\% (10/19), 37\% (7/19), and 37\% (7/19) of studies conducted in the community setting reported on TSSTs, SEs, ETs, respectively, using PCR, reverse passive latex agglutination tests or enzyme-linked immunosorbent assays. Approximately one third of the studies conducted in the community setting (6/19) reported on PCR detection of the PVL genes. In studies conducted in the healthcare setting; $8 \%(1 / 12)$, $25 \%(3 / 12),. 8 \%(1 / 12)$, and $25 \%(3 / 12)$ reported on TSSTs, SEs, ETs, and PVL, respectively.

\section{S. aureus and MRSA Fecal Carriage as Risk Factors for Disease Development}

Two studies included in this review identified enterotoxin producing $S$. aureus strains from fecal specimens of patients with diarrhea (Efuntoye and Adetosoye, 2003; Flemming and Ackermann, 2007). Another study reported that all patients colonized with MRSA in both the nares and rectum (8/8) developed an infection (Srinivasan et al., 2010). In addition, two of the nine patients, colonized with MRSA in the rectum only, were concurrently or subsequently infected. Spa typing on a 


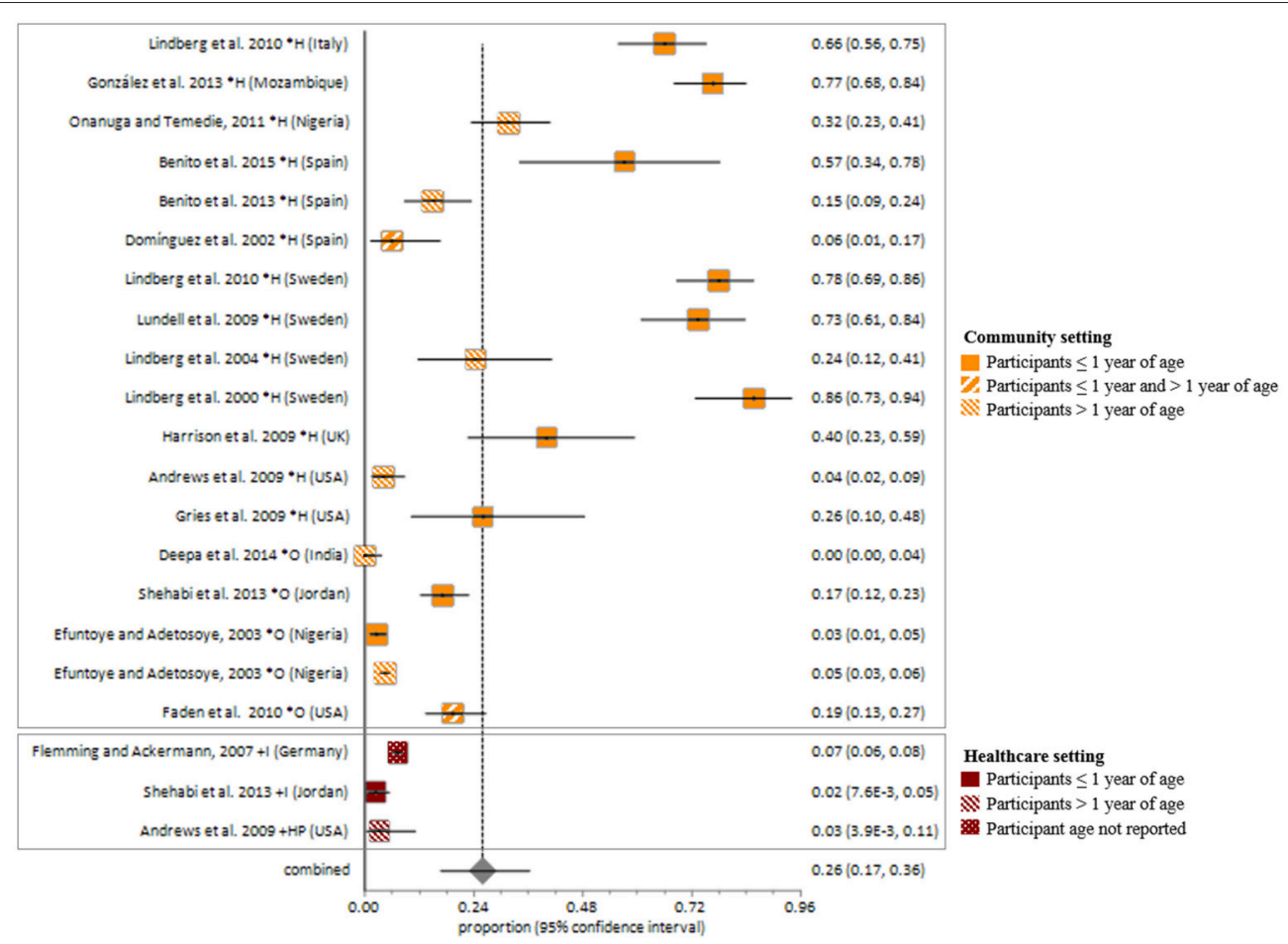

FIGURE 5 | Meta-analysis of proportions on S. aureus fecal carriage rates. *, Community setting; +, Healthcare setting; H, Healthy participants; O, Outpatients; I, Inpatients; HP, Healthcare personnel.

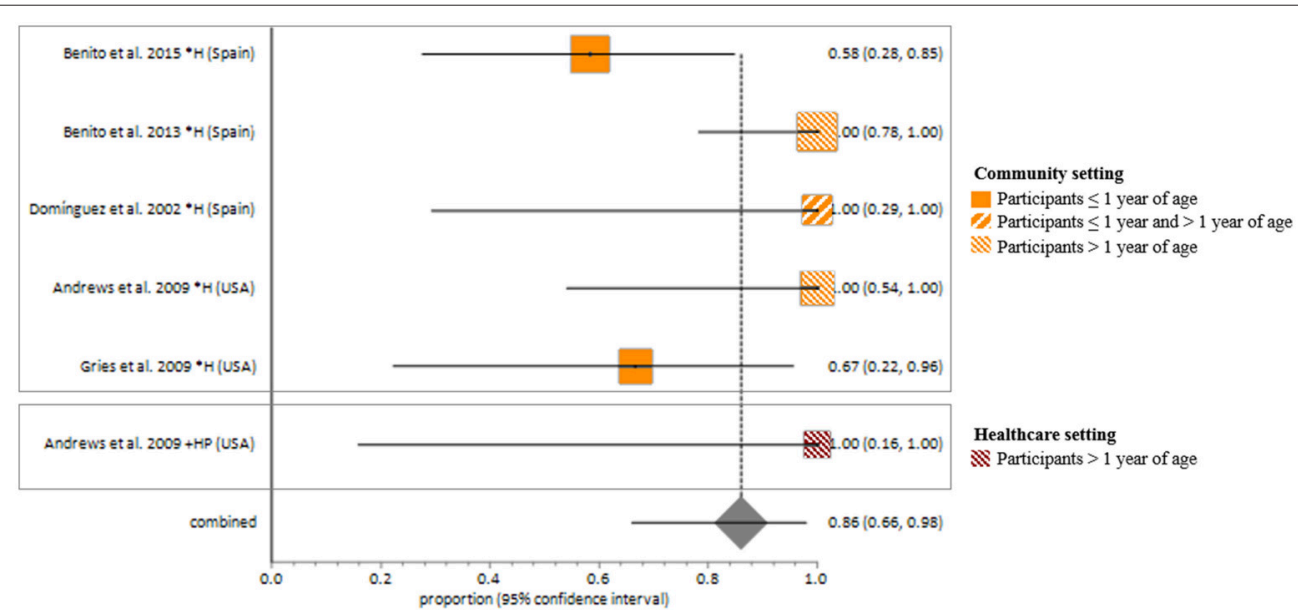

FIGURE 6 | Meta-analyses of proportions on Methicillin susceptible Staphylococcus aureus fecal carriage rates. Pooled random-effects estimate of MSSA fecal carriage within the community and healthcare setting. ${ }^{\star}$, Community setting; +, Healthcare setting; H, Healthy participants; HP, Healthcare personnel.

subset of colonizing isolates from the nares and rectum noted that the majority $(69 \%$; $9 / 13)$ were clonally related to infecting isolates (Srinivasan et al., 2010). In support of the potential of fecal carriage for infection, it has also been shown that $S$. aureus detection occurs more frequently from rectal specimens of children with skin and soft tissue abscesses (47\%; 28/60) compared with the control group $(1 \% ; 1 / 90)(P=0.0001)$ (Faden et al., 2010).

\section{DISCUSSION}

Our results clearly showed that fecal $S$. aureus carriage from healthy infants is high during the first year of life. Specifically, S. aureus fecal carriage rates increased during the first 8 weeks of life followed by a gradual decrease towards 1 year of life. The reasons for this abrupt increase in fecal carriage very early in life (especially from healthy infants) is not yet clear, 


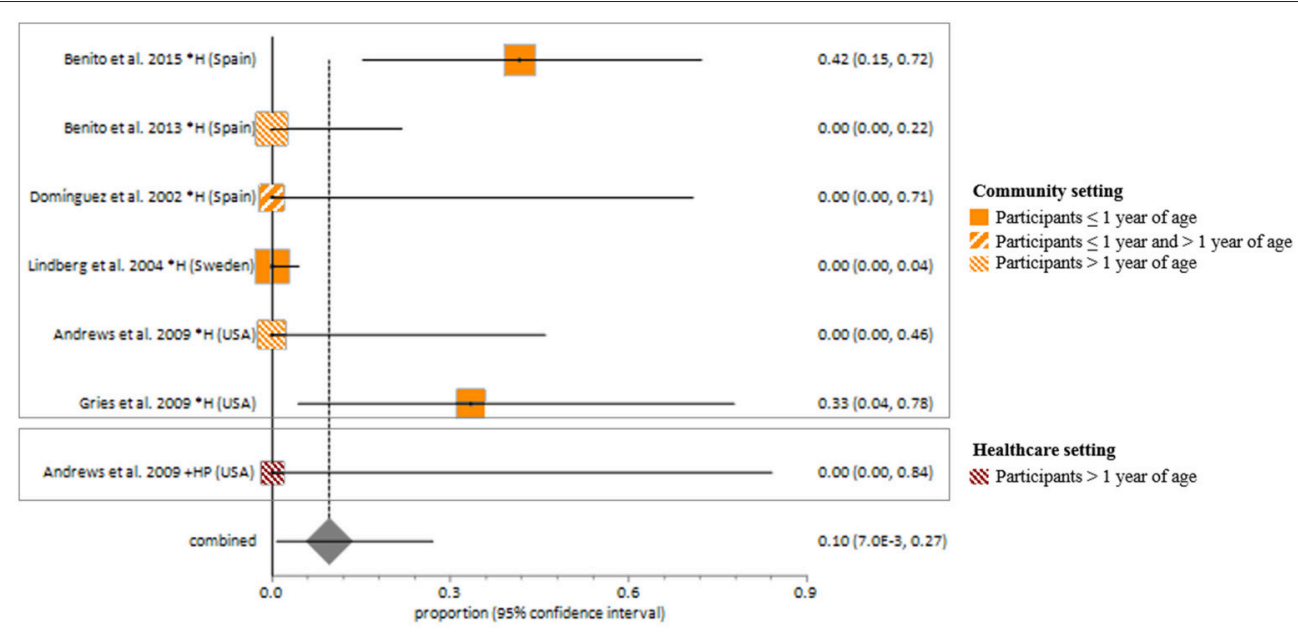

FIGURE 7 | Meta-analyses of proportions on Methicillin resistant Staphylococcus aureus fecal carriage rates. Pooled random effects estimate of MRSA fecal carriage within community and healthcare settings. ${ }^{*}$, Community setting; +, Healthcare setting; H, Healthy participants; HP, Healthcare personnel.

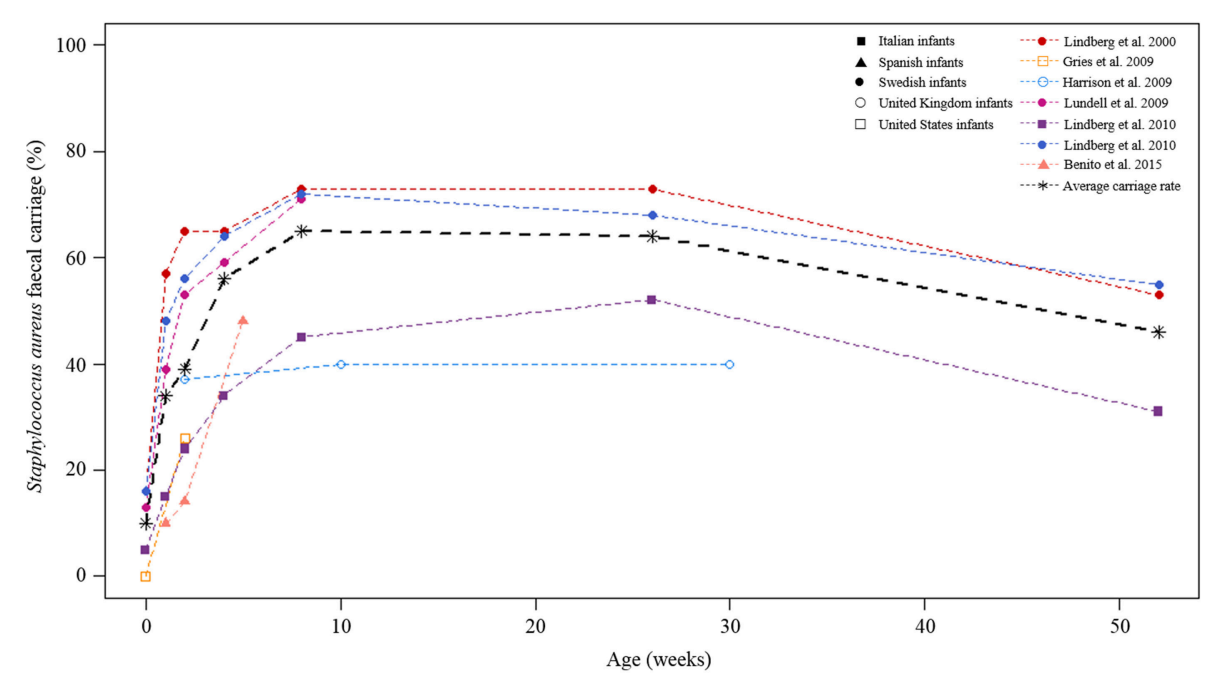

FIGURE 8 | Longitudinal S. aureus fecal carriage rates during the first year of life. The lines in color indicated fecal carriage rates (\%) at each of the time-points measured by the respective studies. The different cohorts are shown by different symbols at each of the time-points studied. The black broken line is the average fecal $S$. aureus carriage rate calculated from all longitudinal studies at the respective time-points under study.

however a potential explanation may be early life care-giving practices, particularly breastfeeding. For example, colostrum contains the highest levels of human milk oligosaccharides (HMOs) (Bode, 2012), which have been suggested to stimulate S. aureus growth (Hunt et al., 2012). Moreover, S. aureus strains may be transmitted from parents via skin contact (Lindberg et al., 2004a) or from the mother via breastfeeding (Kawada et al., 2003; Lindberg et al., 2004a; Benito et al., 2015). Furthermore, staphylococci from the maternal GIT or skin surrounding the areola may be transferred to breast milk during lactation (Thum et al., 2012; Fernández et al., 2013). Higher S. aureus fecal carriage rates have also been noted from breast-fed in comparison to formula-fed or mixed-fed infants (González et al., 2013; Salminen et al., 2015). The observed change in the dynamics of S. aureus fecal carriage after 8 weeks of life may be explained by the increase in anaerobic bacteria from around 1 week of life (Bezirtzoglou, 1997; Adlerberth et al., 2006; Adlerberth and Wold, 2009; Jost et al., 2012), as well as the introduction of formula feeding (González et al., 2013) and solid foods (Bergström et al., 2014; Voreades et al., 2014). Infant fecal bacterial profiles have also been shown to change during the course of the lactation period (Cabrera-Rubio et al., 2012; González et al., 2013).

This systematic review does not only provide insight into the dynamics of fecal S. aureus carriage rates during the first year of life; but also highlights that $S$. aureus and MRSA fecal carriage is a potential risk factor for subsequent infections. Vancomycin is 


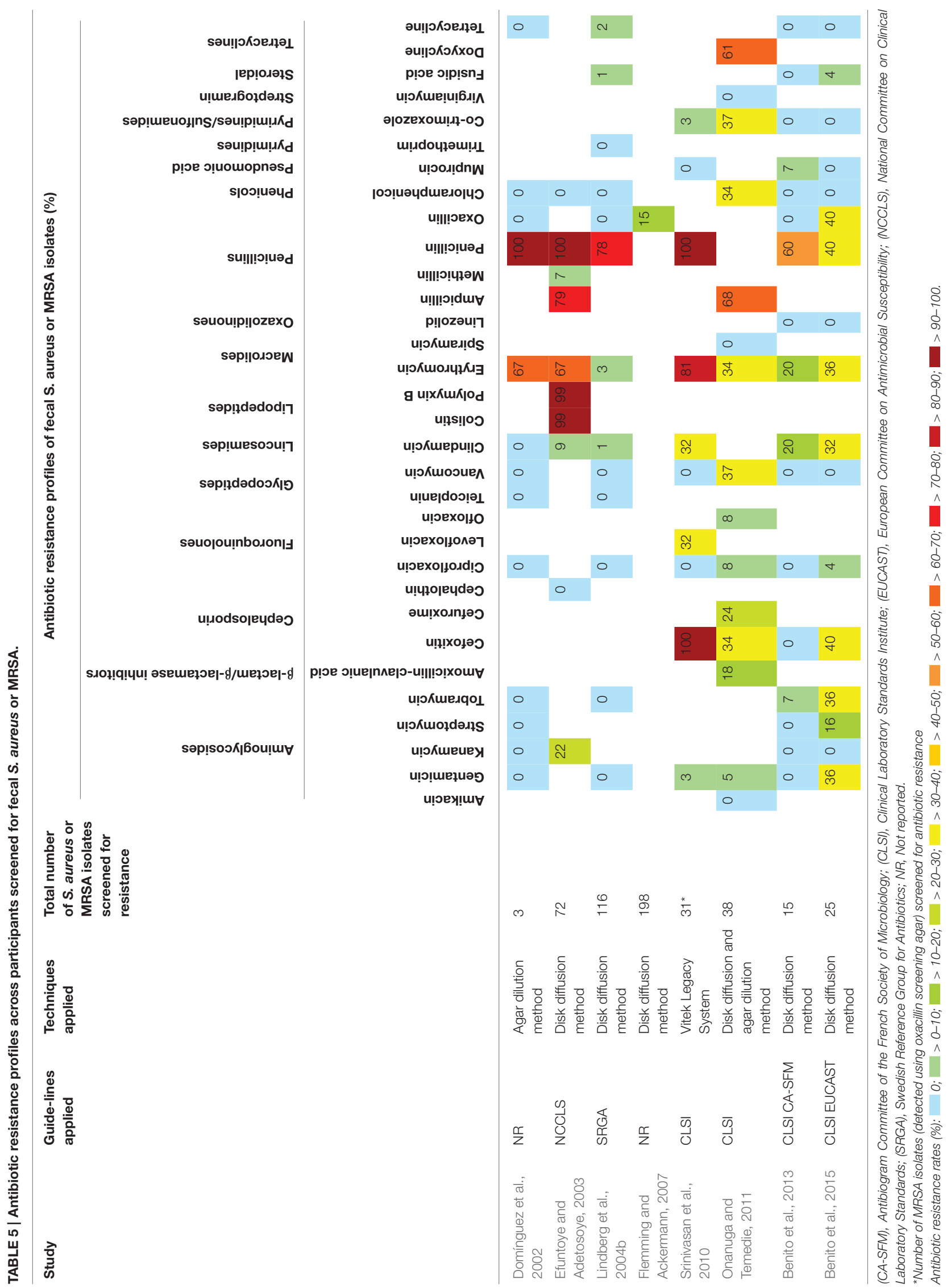


regarded as one of the drugs of choice for MRSA infections (Tarai et al., 2013); however the emergence of vancomycin resistant S. aureus (VRSA) poses yet another threat to infection control (Hiramatsu, 1998; Spagnolo et al., 2014). The intestinal tract, in particular, may be a key potential reservoir for the emergence and transmission of VRSA isolates due to the intestinal coexistence (Ray et al., 2003), and potential transfer of the vanA gene from VRE to MRSA (Courvalin, 2006). Although, 23\% of the studies included in this review screened for fecal carriage of VRSA within community and healthcare settings (Domínguez et al., 2002; Lindberg et al., 2004b; Srinivasan et al., 2010; Onanuga and Temedie, 2011; Benito et al., 2013, 2015); only a single study, performed in Nigeria, reported VRSA fecal carriage (Onanuga and Temedie, 2011). It is noteworthy, however, that this finding should be interpreted with caution as the disk diffusion method was used to screen for vancomycin resistance at $30 \mu \mathrm{g} / \mathrm{ml}$, which is not recommended by the CLSI guidelines (Clinical Laboratory Standards Institute, 2012).

Healthcare associated fecal screening for S. aureus and MRSA is of key importance in infection control (Campillo et al., 2001; Ray et al., 2003; Bhalla et al., 2007). For example, it has been shown that select staphylococcal enterotoxins (SEs) may contribute to the colonizing success of $S$. aureus strains in the GIT (Nowrouzian et al., 2011), which could potentially facilitate in its transmission. Moreover, S. aureus and MRSA fecal carriage may complicate de-colonization, with a potential to contribute to infections within the healthcare setting (Campillo et al., 2001; Dupeyron et al., 2002; Ray et al., 2003; Srinivasan et al., 2010). To prevent nosocomial transmission and infection, two recent studies (Roth et al., 2016; Senn et al., 2016) have also highlighted the importance of screening for $S$. aureus fecal carriage on admission in the following risk groups: patients admitted to surgery or intensive care units with a history of MRSA colonization or infection; hospitalization during the past year; or direct transfer from another healthcare facility. Only a single study was considered eligible for inclusion in our metaanalyses of the proportions on MSSA and MRSA fecal carriage within the healthcare setting. Therefore we could not determine the fecal carriage rate for MSSA or MRSA within this setting.

A major limitation in this systematic review is the poor study design and limited data available from studies assessing the fecal carriage rates of $S$. aureus and MRSA. For example, a large proportion of potentially eligible articles were excluded due to the lack of information regarding participants' contact with healthcare facilities as well as the duration of hospital admission prior to $S$. aureus and MRSA screening. This information is essential in comparing fecal carriage rates from community and healthcare settings. Furthermore, a number of studies could not be included in calculating the pooled estimates for MSSA and MRSA fecal carriage (from both community and healthcare settings) due to the lack of molecular techniques incorporated to confirm MRSA carriage. On the other hand, the extent in which our observations could have changed if unavailable articles were included is unclear. However, based on the rigorous appraisal of various studies in this systematic review, we conclude that the excluded articles are not likely to impact significantly on observations presented in the manuscript. In addition, more studies from both developed and developing countries are needed in order to determine $S$. aureus and MRSA fecal carriage and transmission within and between the community and healthcare settings. In support of this, rural areas and low socioeconomic status have been shown to contribute to higher fecal transmission rates of S. aureus and MRSA (Vale and Vítor, 2010). Finally, there is the need for more sequence-based genotyping data on S. aureus and MRSA fecal carriage as the majority of studies from developed countries made use of gel-based methods which are not ideal when comparing isolates on a global level.

\section{CONCLUSION}

S. aureus, MSSA and MRSA fecal carriage rates within both the community and healthcare setting are not negligible and estimated at 26, 86, and $10 \%$, respectively. Therefore, preventative strategies which include fecal $S$. aureus screening of high risk patients are necessary for infection control within these settings. More studies are needed to determine the role of fecal S. aureus carriage as a risk factor for disease development; as well as fecal carriage rates of MSSA, MRSA, and VRSA from both community and healthcare settings. Furthermore, wellstructured research should be conducted and sequence-based genotyping techniques should be employed. The latter will allow for comparison of isolates on a global level in both developing and developed countries.

\section{AUTHOR CONTRIBUTIONS}

MK and SC initiated the project. SC, MRN, and MK searched the databases for potentially eligible articles based on their titles and abstracts. SC extracted the data and contacted authors of potentially eligible publications to obtain healthcare information on participants when this information was unclear or not provided by the articles. SC, MK, and AS reviewed the articles. SC, LT, and MK performed the statistical analysis and interpreted the results. SC, LT, AS, MPN, and MK wrote the manuscript. All the authors reviewed the final version of the manuscript prior to submission for publication.

\section{FUNDING}

This work was supported by the Bill and Melinda Gates Foundation Global Health Grant (OPP1017641), the National Research Foundation (South Africa), the Carnegie Corporation of New York (United States of America), the US National Institutes of Health (1U01AI110466-01A1), and the Wellcome Trust, United Kingdom (102429/Z/13/Z).

\section{ROLE OF FUNDING SOURCE}

Any opinions, findings and conclusions, or recommendations expressed in this review are those of the authors, and therefore do not represent the official position of the funders. The funders had no role in the study design, data collection and analysis, decision to publish, or preparation of the manuscript. The first and the corresponding author had full access to the study data. 
All authors had final responsibility for the decision to submit the article for publication.

\section{ACKNOWLEDGMENTS}

SC is supported by the National Research Foundation and the Drakenstein Child Health Study, University of Cape Town (South Africa), a birth cohort study funded by Bill and Melinda Gates Foundation (OPP1017641). MK was a recipient

\section{REFERENCES}

Acton, D. S., Plat-Sinnige, M. J. T., Van Wamel, W., de Groot, N., and van Belkum, A. (2009). Intestinal carriage of Staphylococcus aureus: how does its frequency compare with that of nasal carriage and what is its clinical impact? Eur. J. Clin. Microbiol. Infect. Dis. 28, 115-127. doi: 10.1007/s10096-008-0602-7

Adlerberth, I., Lindberg, E., Åberg, N., Hesselmar, B., Saalman, R., Strannegård, I.-L., et al. (2006). Reduced enterobacterial and increased staphylococcal colonization of the infantile bowel: an effect of hygienic lifestyle? Pediatr. Res. 59, 96-101. doi: 10.1203/01.pdr.0000191137.12774.b2

Adlerberth, I., and Wold, A. E. (2009). Establishment of the gut microbiota in Western infants. Acta Paediatr. 98, 229-238. doi: 10.1111/j.16512227.2008.01060.x

Andrews, J. I., Fleener, D. K., Messer, S. A., Kroeger, J. S., and Diekema, D. J. (2009). Screening for Staphylococcus aureus carriage in pregnancy: usefulness of novel sampling and culture strategies. Am. J. Obstet. Gynecol. 201, 396.e1-e5. doi: 10.1016/j.ajog.2009.06.062

Avery, L. M., Zempel, M., and Weiss, E. (2015). Case of antibiotic-associated diarrhea caused by Staphylococcus aureus enterocolitis. Am. J. Health Syst. Pharm. 72, 943-951. doi: 10.2146/ajhp140672

Babay, H. A. H., and Somily, A. M. (2009). Intestinal carriage of methicillin resistant Staphylococcus aureus and extended -spectrum beta-lactamaseproducing Enterobacteriacae in hospitalized and nonhospitalized patients and their clinical implications. Asian Pac. J. Trop. Med. 2, 41-45.

Beall, J. (2015). Beall's List: Potential, Possible, or Probable Predatory Scholarly Open-Access Publishers. Available online at: http://scholarlyoa.com/publishers/

Benito, D., Lozano, C., Gómez-Sanz, E., Zarazaga, M., and Torres, C. (2013). Detection of Methicillin-susceptible Staphylococcus aureus ST398 and ST133 strains in gut microbiota of healthy humans in Spain. Microb. Ecol. 66, 105-111. doi: 10.1007/s00248-013-0240-1

Benito, D., Lozano, C., Jiménez, E., Albújar, M., Gómez, A., Rodríguez, J. M., et al. (2015). Characterization of Staphylococcus aureus strains isolated from faeces of healthy neonates and potential mother-to-infant microbial transmission through breastfeeding. FEMS Microbiol. Ecol. 91:fiv007. doi: 10.1093/femsec/fiv007

Bergström, A., Skov, T. H., Bahl, M. I., Roager, H. M., Christensen, L. B., Ejlerskov, K. T., et al. (2014). Establishment of intestinal microbiota during early life: a longitudinal, explorative study of a large cohort of Danish infants. Appl. Environ. Microbiol. 80, 2889-2900. doi: 10.1128/AEM.00342-14

Bezirtzoglou, E. (1997). The intestinal microflora during the first weeks of life. Anaerobe 3, 173-177. doi: 10.1006/anae.1997.0102

Bhalla, A., Aron, D. C., and Donskey, C. J. (2007). Staphylococcus aureus intestinal colonization is associated with increased frequency of S. aureus on skin of hospitalized patients. BMC Infect. Dis. 7:105. doi: 10.1186/1471-2334-7-105

Bode, L. (2012). Human milk oligosaccharides: every baby needs a sugar mama. Glycobiology 22, 1147-1162. doi: 10.1093/glycob/cws074

Bourgeois-Nicolaos, N., Lucet, J. C., Daubié, C., Benchaba, F., Rajguru, M., Ruimy, R., et al. (2010). Maternal vaginal colonisation by Staphylococcus aureus and newborn acquisition at delivery. Paediatr. Perinat. Epidemiol. 24, 488-491. doi: 10.1111/j.1365-3016.2010.01139.x

Boyce, J. M., Havill, N. L., Otter, J. A., and Adams, N. M. T. (2007). Widespread environmental contamination associated with patients with diarrhea and methicillin-resistant Staphylococcus aureus colonization of the gastrointestinal tract. Infect. Control Hosp. Epidemiol. 28, 1142-1147. doi: 10.1086/520737 of Carnegie Corporation of New York (USA) fellowship, and he is currently supported by Wellcome Trust, United Kingdom (102429/Z/13/Z).

\section{SUPPLEMENTARY MATERIAL}

The Supplementary Material for this article can be found online at: http://journal.frontiersin.org/article/10.3389/fmicb. 2016.00449

Cabrera-Rubio, R., Collado, M. C., Laitinen, K., Salminen, S., Isolauri, E., and Mira, A. (2012). The human milk microbiome changes over lactation and is shaped by maternal weight and mode of delivery. Am. J. Clin. Nut. 96, 544-551. doi: 10.3945/ajcn.112.037382

Campillo, B., Dupeyron, C., and Richardet, J. P. (2001). Epidemiology of hospital-acquired infections in cirrhotic patients: effect of carriage of methicillin-resistant Staphylococcus aureus and influence of previous antibiotic therapy and norfloxacin prophylaxis. Epidemiol. Infect. 127, 443-450. doi: $10.1017 /$ S0950268801006288

Carmeli, Y., Venkataraman, L., DeGirolami, P. C., Lichtenberg, D. A., Karchmer, A. W., and Samore, M. H. (1998). Stool colonization of healthcare workers with selected resistant bacteria. Infect. Control Hosp. Epidemiol. 19, 38-40.

Cochran, W. G. (1954). The combination of estimates from different experiments. Biometrics 10, 101-129.

Courvalin, P. (2006). Vancomycin resistance in gram-positive cocci. Clin. Infect. Dis., 42, S25-S34. doi: 10.1086/491711

Deepa, S., Vandana, S., and Venkatesha, D. (2014). Screening at admission for carrier prevalence of multidrug resistant organisms: a hospital based observational study. Biosci. Biotechnol. Res. Asia 11, 309-316. doi: $10.13005 /$ bbra/1273

Domínguez, E., Zarazaga, M., and Torres, C. (2002). Antibiotic resistance in Staphylococcus isolates obtained from fecal samples of healthy children. J. Clin. Microbiol. 40, 2638-2641. doi: 10.1128/JCM.40.7.2638

Dukic, V. M., Lauderdale, D. S., Wilder, J., Daum, R. S., and David, M. Z. (2013). Epidemics of community-associated methicillin-resistant Staphylococcus aureus in the United States: a meta-analysis. PLoS ONE 8:e52722. doi: 10.1371/journal.pone.0052722

Dupeyron, C., Campillo, B., Bordes, M., Faubert, E., Richardet, J.-P, and Mangeney, N. (2002). A clinical trial of mupirocin in the eradication of methicillinresistant Staphylococcus aureus nasal carriage in a digestive disease unit. J. Hosp. Infect. 52, 281-287. doi: 10.1053/jhin.2002.1287

Efuntoye, M. O., and Adetosoye, A. I. (2003). Enterotoxigenicity and drug sensitivity of staphylococci from children aged five years and below with sporadic diarrhoea. East Afr. Med. J. 80, 656-659. doi: 10.4314/eamj.v80i12.8784

Egger, M., Davey Smith, G., Schneider, M., and Minder, C. (1997). Bias in metaanalysis detected by a simple, graphical test. BMJ 315, 629-634.

Ellis, M. W., Hospenthal, D. R., Dooley, D. P., Gray, P. J., and Murray, C. K. (2004). Natural history of community-acquired methicillin-resistant Staphylococcus aureus colonization and infection in soldiers. Clin. Infect. Dis. 39, 971-979. doi: $10.1086 / 423965$

Faden, H., Lesse, A. J., Trask, J., Hill, J. A., Hess, D. J., Dryja, D., et al. (2010). Importance of colonization site in the current epidemic of staphylococcal skin abscesses. Pediatrics 125, e618-e624. doi: 10.1542/peds.20091523

Fernández, L., Langa, S., Martín, V., Maldonado, A., Jiménez, E., Martín, R., et al. (2013). The human milk microbiota: origin and potential roles in health and disease. Pharmacol. Res. 69, 1-10. doi: 10.1016/j.phrs.2012.09.001

Flemming, K., and Ackermann, G. (2007). Prevalence of enterotoxin producing Staphylococcus aureus in stools of patients with nosocomial diarrhea. Infection 35, 356-358. doi: 10.1007/s15010-007-6268-8

Folden, D. V., Machayya, J. A., Sahmoun, A. E., Beal, J. R., Holzman, G. S., Helgerson, S. D., et al. (2005). Estimating the proportion of communityassociated methicillin-resistant Staphylococcus aureus: two definitions used in 
the USA yield dramatically different estimates. J. Hosp. Infect. 60, 329-332. doi: 10.1016/j.jhin.2004.12.025

González, R., Mandomando, I., Fumadó, V., Sacoor, C., Macete, E., Alonso, P. L., et al. (2013). Breast milk and gut microbiota in African mothers and infants from an area of high HIV prevalence. PLoS ONE 8:e80299. doi: 10.1371/journal.pone.0080299

Gries, D. M., Zemzars, T. F., Gibson, K. A., O’Hern, E., Iyer, M., Myers, M., et al. (2009). A pilot study to assess frequency of carriage and routes of acquisition of Staphylococcus aureus by healthy infants. Am. J. Infect. Control 37, 598-600. doi: 10.1016/j.ajic.2008.12.003

Harrison, L. M., Morris, J. A., Lauder, R. M., and Telford, D. R. (2009). Staphylococcal pyrogenic toxins in infant urine samples: a possible marker of transient bacteraemia. J. Clin. Pathol. 62, 718-735. doi: 10.1136/jcp.2008.057232

Higgins, J. P. T., Thompson, S. G., Deeks, J. J., and Altman, D. G. (2003). Measuring inconsistency in meta-analyses. BMJ 327, 557-560. doi: 10.1136/bmj.327.7414.557

Hiramatsu, K. (1998). Vancomycin resistance in staphylococci. Drug Resist. Updat. 1, 135-150. doi: 10.1016/S1368-7646(98)80029-0

Hunt, K. M., Preuss, J., Nissan, C., Davlin, C. A., Williams, J. E., Shafii, B., et al. (2012). Human milk oligosaccharides promote the growth of staphylococci. Appl. Environ. Microbiol. 78, 4763-4770. doi: 10.1128/AEM.00477-12

Hurst, V. (1960). Transmission of hospital staphylococci among newborn infants: II. Colonization of the skin and mucous membranes of the infants. Pediatrics 25, 204-214.

Jost, T., Lacroix, C., Braegger, C. P., and Chassard, C. (2012). New insights in gut microbiota establishment in healthy breast fed neonates. PLOS ONE 7:e44595. doi: 10.1371/journal.pone.0044595

Kawada, M., Okuzumi, K., Hitomi, S., and Sugishita, C. (2003). Transmission of Staphylococcus aureus between healthy, lactating mothers and their infants by breastfeeding. J. Hum. Lact. 19, 411-417. doi: 10.1177/0890334403257799

Klotz, M., Zimmermann, S., Opper, S., Heeg, K., and Mutters, R. (2005). Possible risk for re-colonization with methicillin-resistant Staphylococcus aureus (MRSA) by faecal transmission. Int. J. Hyg. Environ. Health 208, 401-405. doi: 10.1016/j.ijheh.2005.05.004

Kluytmans, J., van Belkum, A., and Verbrugh, H. (1997). Nasal carriage of Staphylococcus aureus: epidemiology, underlying mechanisms, and associated risks. Clin. Microbiol. Rev. 10, 505-520.

Lee, Y. L., Cesario, T., Gupta, G., Flionis, L., Tran, C., Decker, M., et al. (1997). Surveillance of colonization and infection with Staphylococcus aureus susceptible or resistant to methicillin in a community skilled-nursing facility. Am. J. Infect. Control 25, 312-321. doi: 10.1016/S0196-6553(97)90023-7

Levy, P. Y., Ollivier, M., Drancourt, M., Raoult, D., and Argenson, J. N. (2013). Relation between nasal carriage of Staphylococcus aureus and surgical site infection in orthopedic surgery: the role of nasal contamination. A systematic literature review and meta-analysis. Orthop. Traumatol. Surg. Res. 99, 645-651. doi: 10.1016/j.otsr.2013.03.030

Lindberg, E., Adlerberth, I., Hesselmar, B., Saalman, R., Strannegård, I.-L., Åberg, N., et al. (2004a). High rate of transfer of Staphylococcus aureus from parental skin to infant gut flora. J. Clin. Microbiol. 42, 530-534. doi: 10.1128/JCM.42.2.530-534.2004

Lindberg, E., Adlerberth, I., Matricardi, P., Bonanno, C., Tripodi, S., Panetta, V., et al. (2010). Effect of lifestyle factors on Staphylococcus aureus gut colonization in Swedish and Italian infants. Clin. Microbiol. Infect. 17, 1209-1215. doi: 10.1111/j.1469-0691.2010.03426.x

Lindberg, E., Adlerberth, I., and Wold, A. E. (2004b). Antibiotic resistance in Staphylococcus aureus colonising the intestines of Swedish infants. Clin. Microbiol. Infect. 10, 890-894. doi: 10.1111/j.1469-0691.2004.01002.x

Lindberg, E., Nowrouzian, F., Adlerberth, I., and Wold, A. E. (2000). Longtime persistence of superantigen-producing Staphylococcus aureus strains in the intestinal microflora of healthy infants. Pediatr. Res. 48, 741-747. doi: 10.1203/00006450-200012000-00007

Lo, T. S., and Borchardt, S. M. (2009). Antibiotic-associated diarrhea due to methicillin-resistant Staphylococcus aureus. Diagn. Microbiol. Infect. Dis. 63, 388-389. doi: 10.1016/j.diagmicrobio.2008.12.007

Lundell, A. C., Hesselmar, B., Nordström, I., Saalman, R., Karlsson, H., Lindberg, E., et al. (2009). High circulating immunoglobulin A levels in infants are associated with intestinal toxigenic Staphylococcus aureus and a lower frequency of eczema. Clin. Exp. Allergy 39, 662-670. doi: 10.1111/j.13652222.2008.03176.x

Maier, J., Melzl, H., Reischl, U., Drubel, I., Witte, W., Lehn, N., et al. (2005). Panton-Valentine leukocidin-positive methicillin-resistant Staphylococcus aureus in Germany associated with travel or foreign family origin. Eur. J. Clin. Microbiol. Infect. Dis. 24, 637-639. doi: 10.1007/s10096-005-0008-8

McKinnell, J. A., Miller, L. G., Eells, S. J., Cui, E., and Huang, S. S. (2013). A systematic literature review and meta-analysis of factors associated with methicillin-resistant Staphylococcus aureus colonization at time of hospital or intensive care unit admission. Infect. Control Hosp. Epidemiol. 34, 1077-1086. doi: $10.1086 / 673157$

Mertz, D., Frei, R., Jaussi, B., Tietz, A., Stebler, C., Flückiger, U., et al. (2007). Throat swabs are necessary to reliably detect carriers of Staphylococcus aureus. Clin. Infect. Dis. 45, 475-477. doi: 10.1086/520016

Millar, B. C., Loughrey, A., Elborn, J. S., and Moore, J. E. (2007). Proposed definitions of community-associated meticillin-resistant Staphylococcus aureus (CA-MRSA). J. Hosp. Infect. 67, 109-113. doi: 10.1016/j.jhin.2007.06.003

Moher, D., Liberati, A., Tetzlaff, J., and Altman, D. G. (2009). Preferred reporting items for systematic reviews and meta-analyses: the PRISMA statement. PLoS Med. 6:1000097, DOI: 10.1371/journal.pmed.1000097

Nowrouzian, F. L., Dauwalder, O., Meugnier, H., Bes, M., Etienne, J., Vandenesch, F., et al. (2011). Adhesin and superantigen genes and the capacity of Staphylococcus aureus to colonize the infantile gut. J. Infect. Dis. 204, 714-721. doi: 10.1093/infdis/jir388

O'Fallon, E., Schreiber, R., Kandel, R., and D'Agata, E. M. C. (2009). MultidrugResistant gram-negative bacteria at a long-term care facility: assessment of residents, healthcare workers, and inanimate surfaces. Infect. Control Hosp. Epidemiol. 30, 1172-1179. doi: 10.1086/648453

Onanuga, A., and Temedie, T. C. (2011). Multidrug-resistant intestinal Staphylococcus aureus among self-medicated healthy adults in Amassoma, South-South, Nigeria. J. Health Popul. Nutr. 29, 446-453. doi: 10.3329/jhpn.v29i5.8898

Otter, J. A., and French, G. L. (2011). Community-associated meticillin-resistant Staphylococcus aureus strains as a cause of healthcare-associated infection. J. Hosp. Infect. 79, 189-193. doi: 10.1016/j.jhin.2011.04.028

Petersen, I. S., Larsen, P. L., Brandelev, B. L., Hald, J., Prætorius, C., Welinder, R., et al. (2013). Close association between oropharyngeal and rhinopharyngeal colonization with Staphylococcus aureus - clues to new insight of MRSA colonization of the oropharynx. J. Hosp. Infect. 84, 259-262. doi: 10.1016/j.jhin.2013.04.007

Popov, L., Kovalski, J., Grandi, G., Bagnoli, F., and Amieva, M. R. (2014). Three-dimensional human skin models to understand Staphylococcus aureus skin colonization and infection. Front. Immunol. 5:41. doi: 10.3389/fimmu.2014.00041

Ray, A. J., Pultz, N. J., Bhalla, A., Aron, D. C., and Donskey, C. J. (2003). Coexistence of vancomycin-resistant enterococci and Staphylococcus aureus in the intestinal tracts of hospitalized patients. Clin. Infect. Dis. 37, 875-881. doi: $10.1086 / 377451$

Roth, V. R., Longpre, T., Taljaard, M., Coyle, D., Suh, K. N., Muldoon, K. A., et al. (2016). Universal vs risk factor screening for Methicillin-Resistant Staphylococcus aureus in a Large Multicenter Tertiary Care Facility in Canada. Infect. Control Hosp. Epidemiol. 37, 41-48. doi: 10.1017/ice.2015.230

Salminen, S., Endo, A., Isolauri, E., and Scalabrin, D. (2015). Early gut colonization with Lactobacilli and Staphylococcus in infants: the Hygiene Hypotphesis extended. J. Pediatr. Gastroenterol. Nutr. 62, 80-86. doi: 10.1097/MPG.0000000000000925

Senn, L., Clerc, O.,Zanetti, G., Basset, P., Prod'hom, G., Gordon, N. C., et al. (2016). The Stealthy Superbug: the role of asymptomatic enteric carriage inmaintaining a long-term hospital outbreak of ST228 methicillin-resistant Staphylococcus aureus. MBio 7, e02039-e02015. doi: 10.1128/mBio.02039-15

Shehabi, A. A., Abu-Yousef, R., Badran, E., Al-Bakri, A. G., Abu-Qatouseh, L. F., and Becker, K. (2013). Major characteristics of Staphylococcus aureus colonizing Jordanian infants. Pediatr. Int. 55, 300-304. doi: 10.1111/ped.12060

Shen, C., and Björk, B. C. (2015). "Predatory" open access: a longitudinal study of article volumes and market characteristics. BMC Med. 13:230. doi: 10.1186/s12916-015-0469-2

Siebert, S., Machesky, L. M., and Insall, R. H. (2015). Overflow in science and its implications for trust. Elife 4:e10825. doi: 10.7554/eLife.10825 
Sizemore, E. N., Rivas, K. M., Valdes, J., and Caballero, J. (2012). Enteral vancomycin and probiotic use for methicillin-resistant Staphylococcus aureus antibiotic-associated diarrhoea. BMJ Case Rep. 2012, 1-5. doi: 10.1136/bcr2012-006366

Sollid, J. U. E., Furberg, A. S., Hanssen, A. M., and Johannessen, M. (2014). Staphylococcus aureus: determinants of human carriage. Infect. Genet. Evol. 21, 531-541. doi: 10.1016/j.meegid.2013.03.020

Spagnolo, A. M., Orlando, P., Panatto, D., Amicizia, D., Perdelli, F., and Cristina, M. L. (2014). Staphylococcus aureus with reduced susceptibility to vancomycin in healthcare settings. J. Prev. Med. Hyg. 55, 137-144. doi: 10.15167/24214248/jpmh2014.55.4.454

Squier, C., Rihs, J. D., Risa, K. J., Sagnimeni, A., Wagener, M. M., Stout, J., et al. (2002). Staphylococcus aureus rectal carriage and its association with infections in patients in a surgical intensive care unit and a liver transplant unit. Infect. Control Hosp. Epidemiol. 23, 495-501. doi: 10.1086/500651

Srinivasan, A., Seifried, S. E., Zhu, L., Srivastava, D. K., Perkins, R., Shenep, J. L., et al. (2010). Increasing prevalence of nasal and rectal colonization with methicillin-resistant Staphylococcus aureus in children with cancer. Pediatr. Blood Cancer 55, 1317-1322. doi: 10.1002/pbc.22815

Clinical and Laboratory Standards Institute (2012). Performance Standards for Antimicrobial Disk Susceptibility Tests; Approved Standard - Eleventh Edition. M02-A11, Vol. 32. Wayne, PA: Clinical and Laboratory Standards Institute.

Sterne, J. A. C., Sutton, A. J., Ioannidis, J. P. A., Terrin, N., Jones, D. R., Lau, J., et al. (2011). Recommendations for examining and interpreting funnel plot asymmetry in meta-analyses of randomised. BMJ 342, 1-8. doi: 10.1136/bmj.d4002

Tarai, B., Das, P., and Kumar, D. (2013). Recurrent Challenges for Clinicians: emergence of Methicillin-Resistant Staphylococcus aureus, vancomycin resistance, and current treatment options. J. Lab. Physicians 5, 71-78. doi: 10.4103/0974-2727.119843

Thum, C., Cookson, A. L., Otter, D. E., Mcnabb, W. C., Hodgkinson, A. J., Dyer, J., et al. (2012). Can nutritional modulation of maternal intestinal microbiota influence the development of the infant gastrointestinal tract? J. Nutr. 142, 1921-1928. doi: 10.3945/jn.112.166231.1921
Tong, S. Y. C., Davis, J. S., Eichenberger, E., Holland, T. L., and Fowler, V. G. Jr. (2015). Staphylococcus aureus infections: epidemiology, pathophysiology, clinical manifestations, and management. Clin. Microbiol. Rev. 28, 603-661. doi: 10.1128/CMR.00134-14

Trick, W. E., Weinstein, R. A., DeMarais, P. L., Kuehnert, M. J., Tomaska, W., Nathan, C., et al. (2001). Colonization of skilled-care facility residents with antimicrobial-resistant pathogens. Am. Geriatr. Soc. 49, 270-276. doi: 10.1046/j.1532-5415.2001.4930270.x

Vale, F. F., and Vítor, J. M. B. (2010). Transmission pathway of Helicobacter pylori: does food play a role in rural and urban areas? Int. J. Food Microbiol. 138, 1-12. doi: 10.1016/j.ijfoodmicro.2010.01.016

van Belkum, A., Melles, D. C., Nouwen, J., van Leeuwen, W. B., van Wamel, W., Vos, M. C., et al. (2009). Co-evolutionary aspects of human colonisation and infection by Staphylococcus aureus. Infect. Genet. Evol. 9, 32-47. doi: 10.1016/j.meegid.2008.09.012

Voreades, N., Kozil, A., and Weir, T. L. (2014). Diet and the development of the human intestinal microbiome. Front. Microbiol. 5:494. doi: 10.3389/fmicb.2014.00494

Wertheim, H. F. L., Vos, M. C., Ott, A., van Belkum, A., Voss, A., Kluytmans, J. A. J. W., et al. (2004). Risk and outcome of nosocomial Staphylococcus aureus bacteraemia in nasal carriers versus non-carriers. Lancet 364, 703-705. doi: $10.1016 /$ S0140-6736(04)16897-9

Conflict of Interest Statement: The authors declare that the research was conducted in the absence of any commercial or financial relationships that could be construed as a potential conflict of interest.

Copyright (c) 2016 Claassen-Weitz, Shittu, Ngwarai, Thabane, Nicol and Kaba. This is an open-access article distributed under the terms of the Creative Commons Attribution License (CC BY). The use, distribution or reproduction in other forums is permitted, provided the original author(s) or licensor are credited and that the original publication in this journal is cited, in accordance with accepted academic practice. No use, distribution or reproduction is permitted which does not comply with these terms. 